\title{
Synaptic Cross Talk between Perisomatic-Targeting Interneuron Classes Expressing Cholecystokinin and Parvalbumin in Hippocampus
}

\author{
Miranda A. Karson, ${ }^{1 *}$ Ai-Hui Tang, ${ }^{1 *}$ Teresa A. Milner, ${ }^{2,3}$ and Bradley E. Alger ${ }^{1}$ \\ ${ }^{1}$ Department of Physiology and Program in Neuroscience, University of Maryland School of Medicine, Baltimore, Maryland 21210, ${ }^{2}$ Department of \\ Neurology and Neuroscience, Weill Cornell Medical College, New York, New York 10065, and ${ }^{3}$ Laboratory of Neuroendocrinology, The Rockefeller \\ University, New York, New York 10065
}

Cholescystokinin (CCK)- or parvalbumin (PV)-containing interneurons are the major perisomatic-targeting interneurons in the cerebral cortex, including hippocampus, and are thought to form mutually exclusive networks. We used several techniques to test the alternative hypothesis that CCK and PV cells are coupled by chemical synapses. Triple immunofluorescence confocal microscopy revealed numerous axosomatic, axodendritic, and axoaxonic contacts stained for CCK, PV, and the presynaptic marker synaptophysin. The existence of mutual CCK and PV synapses was supported by dual EM immunolabeling. Paired whole-cell recordings detected unitary $\mathrm{GABA}_{\mathrm{A}} \mathrm{ergic}$ synaptic transmission between identified CCK and PV cells, and single CCK cells could transiently inhibit action potential firing of synaptically coupled PV cells. We conclude that the major hippocampal perisomatic-targeting interneurons communicate synaptically. This communication should affect neuronal network activity, including neuronal oscillations, in which the CCK and PV cells have well established roles. The prevalence of CCK and PV networks in other brain regions suggests that internetwork interactions could be generally important.

\section{Introduction}

Two major classes of cortical GABAergic inhibitory interneuron express cholescystokinin (CCK) or parvalbumin (PV) (Freund, 2003; Somogyi and Klausberger, 2005; Freund and Katona, 2007). Subclasses of these interneurons target perisomatic regions of principal cells and produce large $\mathrm{GABA}_{\mathrm{A}}$ receptormediated responses that regulate principal cell firing (Cobb et al., 1995; Miles et al., 1996; Pouille and Scanziani, 2001). Despite similarities, CCK and PV cells differ sharply: CCK cells express cannabinoid receptors $\left(\mathrm{CB}_{1} \mathrm{Rs}\right)$ (Marsicano and Lutz, 1999; Tsou et al., 1999) and respond to eCBs (endocannabinoids); PV cells do not. $\mu$-Opiate receptors are found on PV and not CCK cells (Drake and Milner, 2002). Muscarinic cholinergic agonists activate $\mathrm{CB}_{1} \mathrm{R} / \mathrm{CCK}$ cells via $\mathrm{M}_{1} / \mathrm{M}_{3}$ muscarinic acetylcholine receptors (mAChRs) (Martin and Alger, 1999; Fukudome et al., 2004), whereas PV cells express $M_{2}$ receptors, which inhibit their output

\footnotetext{
Received 0ct. 31, 2008; revised Feb. 7, 2009; accepted Feb. 19, 2009.

This work was supported by National Institutes of Health Grants R01 DE14625, R01 MH77277 (B.E.A.), R01 DA08259, and P01 HL18974 (T.A.M.), and an award from the Maryland Cigarette Restitution Fund (B.E.A.). M.A.K. was supported in part by Postdoctoral Training Grant T32 NS07375 to the University of Maryland. We thank Katherine Mitterling for assistance with immunostaining and EM embedding, Prof. Gloria Hoffman for technical advice and consultation, and Dr. Jimok Kim for his comments on a draft of this manuscript. M.A.K. did the morphological experiments, including EM in collaboration with T.A.M.; A.T. did the electrophysiological experiments. B.E.A. was responsible for the overall project design and execution and for writing the paper in collaboration with M.A.K. and A.T.

${ }^{*}$ M.A.K. and A.T. contributed equally to this work.

Correspondence should be addressed to Dr. Bradley E. Alger, Department of Physiology, University of Maryland School of Medicine, 655 West Baltimore Street, Baltimore, MD 21210. E-mail: balgerlab@gmail.com.

DOI:10.1523/JNEUROSCI.5264-08.2009

Copyright $\odot 2009$ Society for Neuroscience $\quad$ 0270-6474/09/294140-15\$15.00/0
}

(Hájos et al., 1998; Fukudome et al., 2004). CB 1 R/CCK cell IPSCs are blocked by the N-type Ca channel toxin $\omega$-conotoxin GVIA (Wilson and Nicoll, 2001; Hefft and Jonas, 2005). PV IPSCs are blocked by the P/Q channel toxin $\omega$-agatoxin-VIA (Hefft and Jonas, 2005).

CCK cell IPSCs are accompanied by copious asynchronous release (Hefft and Jonas, 2005). $\mathrm{CB}_{1} \mathrm{R} / \mathrm{CCK}$ cells require extensive integration of fast EPSPs to reach threshold (Glickfeld and Scanziani, 2006). They express receptors for numerous neurotransmitters and modulators, enabling them to respond to influences triggered by many environmental causes, and fine-tune pyramidal cell behavior (Freund, 2003; Freund and Katona, 2007). PV cell IPSCs have rapid kinetics typifying highly synchronous vesicular GABA release (Hefft and Jonas, 2005). PV cells fire regularly, are quickly recruited by glutamatergic synaptic inputs, and have few receptors for other neuromodulators (Freund, 2003).

CCK and PV classes are nonoverlapping and thought to act independently, yet the possibility that they directly interact has not been rigorously tested. In dentate gyrus, there is morphological, but no physiological, evidence of CCK-PV contacts (Acsády et al., 2000). In the CA1 region in vivo, both CCK and PV cells fire in register with hippocampal theta rhythms, although out of phase with each other (Klausberger et al., 2005). Exogenous CCK enhances PV cell firing (Földy et al., 2007; Karson et al., 2008), and CCK cells could help recruit PV cell oscillations (Freund and Katona, 2007), if the cells communicate. Discovery of such communication would significantly influence understanding of the neuronal and behavioral roles of perisomatic inhibition. We now 
Table 1. List of primary antibodies

\begin{tabular}{lllll}
\hline Molecule & Species & Dilution & Source & Specificity references \\
\hline CCK & Rabbit $^{a}$ & $1: 5000,1: 2000^{b}$ & Sigma-Aldrich & Larrson and Rehfeld (1978) \\
& Mouse & $1: 5000$ & Dr. G. Ohning (CURE, University of California, Los & Ohning et al. (1996) \\
PV & & Angeles, Los Angeles, CA) (ab 9303) & Mithani et al. (1987) \\
& Rabbit & $1: 10,000$ & Calbiochem & Celio et al. (1988) \\
& Mouse & $1: 10,000$ & Swant (mab 235) & Celio and Heizmann (1981) \\
SYP & Mouse $^{a}$ & $1: 10,000,1: 3000^{b}$ & Sigma-Aldrich (parv 19) & Honer et al. (1993, 1997) \\
& Mouse ${ }^{a}$ & $1: 1000$ & Millipore Bioscience Research Reagents (mab & 329/SP15) \\
& Mouse & 1:1000 & Millipore Bioscience Research Reagents (mab & Gao et al. (2006) \\
\hline
\end{tabular}

${ }^{a}$ Denotes antibodies used for double- and triple-labeling experiments; other antibodies were used to corroborate staining results and antigen specificity.

${ }^{b}$ Dilutions used for electron microscopy.

report the first extensive evidence for direct synaptic input from CCK to PV interneurons.

Using paired electrophysiological recordings, multiple fluorescence immunocytochemical staining with confocal imaging, as well as dual-immunolabeling and ultrastructural analysis, we tested the hypothesis that hippocampal CA1 CCK cells synapse onto PV cells. We observed many axosomatic, axodendritic, and axoaxonic synapses between CCK and PV cells at both light and ultrastructural levels, as well as $\mathrm{CCK} \rightarrow \mathrm{PV}$ ( $\rightarrow$ designates presynaptic to postsynaptic polarity) $\mathrm{GABA}_{\mathrm{A}}$ ergic synaptic transmission, although only morphological evidence for PV $\rightarrow$ CCK synapses. Activation of CCK cells, by local microiontophoretic ACh pulses or direct current injection, inhibited action potential firing of synaptically coupled PV cells via $\mathrm{GABA}_{\mathrm{A}}$ ergic action. Synaptic signaling from CCK to PV interneurons expands the known repertoire of these behaviorally important cells.

\section{Materials and Methods}

Hippocampal slice preparation. Hippocampal slices were prepared in accordance with the Guidelines for the Care and Use of Experimental Animals using protocols approved by the Institutional Animal Care and Use Committee of the University of Maryland School of Medicine. Young ( $\sim 5-7$ weeks) adult male Sprague Dawley rats were deeply anesthetized with isoflurane $\left(\sim 2 \%\right.$ in $\left.\mathrm{O}_{2}\right)$ and decapitated. Both hippocampi were rapidly removed from the brain. Transverse hippocampal slices ( $400 \mu \mathrm{m}$ thick) were cut on a Vibratome VT1200S (Leica). Slices were placed in a holding chamber at room temperature $\left(22^{\circ} \mathrm{C}\right)$ at the interface of artificial CSF (ACSF) and a humidified gas mixture of $95 \% \mathrm{O}_{2}$ and $5 \% \mathrm{CO}_{2}$ for $1 \mathrm{~h}$ before being transferred to a submersion chamber (model RC-27; Warner Instruments) that was continuously perfused with ACSF at room temperature, $\sim 22^{\circ} \mathrm{C}$. ACSF contained the following (in mM): $120 \mathrm{NaCl}$, $3 \mathrm{KCl}, 2 \mathrm{MgSO}_{4}, 2.5 \mathrm{CaCl}_{2}, 1 \mathrm{NaH}_{2} \mathrm{PO}_{4}, 25 \mathrm{NaHCO}_{3}, 10$ glucose, and was bubbled with $95 \% \mathrm{O}_{2}$ and $5 \% \mathrm{CO}_{2}, \mathrm{pH}$ 7.4. In all experiments the ionotropic glutamate receptor antagonists AP5 $(50 \mu \mathrm{M})$ and NBQX $(1,2,3,4-$ tetrahydro-6-nitro-2,3-dioxo-benzo[f] quinoxaline-7-sulfonamide) (10 $\mu \mathrm{M})$ were present to block EPSCs and polysynaptic pathways.

Electrophysiology. Dual recordings of synaptically coupled cells were performed at room temperature with whole-cell patch pipettes having resistances of 4-7 M $\Omega$ in the bath solution. In most experiments, voltage-clamped unitary IPSCs (uIPSCs) were recorded with patch pipettes filled with the following (in $\mathrm{mM}$ ): 85 gluconate, $50 \mathrm{KCl}, 10 \mathrm{HEPES}$, 3 ATP-Mg, 0.3 GTP-Tris, $0.1 \mathrm{CaCl}_{2}$, 1 BAPTA-K, $1 \mathrm{MgCl}_{2}$, and $0.2 \%$ biocytin, pH 7.2, 280-290 mOsm, or 0.2\% Neurobiotin. Each tracer molecule was used in $\sim 50 \%$ of the experiments, and since we only observed a slight broadening of the action potential with Neurobiotin, all data were combined. In some experiments (see Fig. 9), current-clamp recordings were made with patch pipettes containing the following (in $\mathrm{mm}$ ): $146 \mathrm{~K}$-gluconate, $1 \mathrm{NaCl}, 1 \mathrm{MgSO}_{4}, 0.2 \mathrm{CaCl}_{2}, 2$ EGTA, 10 HEPES, 4 ATP-Mg, $0.3 \mathrm{~mm}$ GTP-Tris, and $0.2 \%$ Neurobiotin. This solution preserved the normal transmembrane $\left[\mathrm{Cl}^{-}\right]$and allowed both presynaptic and postsynaptic cells to fire action potentials. A Nikon E600 microscope fitted with differential interference contrast optics was generally used to visualize cells, which were obtained in stratum (s.) radiatum, s. pyramidale, or s. oriens (as noted), although in some experiments pyramidal cells were recorded in s. pyramidale using a blind approach. Recordings were made using Axopatch 200B and Axopatch 1C amplifiers (Molecular Devices). Signals were filtered at $5 \mathrm{kHz}$ and digitized at $5 \mathrm{kHz}$ with a Digidata 1440A analog-digital interface and Clampex 10 software (Molecular Devices). Chemicals were purchased from Sigma-Aldrich.

Post hoc dual immunofluorescence and biocytin retrieval. After electrophysiological recordings, slices were fixed overnight in $4 \%$ paraformaldehyde (PFA) in $0.1 \mathrm{~m}$ phosphate buffer (PB) at $4^{\circ} \mathrm{C}$. After being washed for $1 \mathrm{~h}$ in multiple changes of $\mathrm{PB}$, slices were laid out flat on a thick piece of agar, and then embedded in $5 \mathrm{~mm}$ of warm agar (4\% agar w/v). Agar-embedded slices were allowed to harden at room temperature for 15-30 min. Blocks were then cut in a series of 50- $\mu \mathrm{m}$-thick slices with a Vibratome (Leica), and excess agar was trimmed away. Slices were stored at $-25^{\circ} \mathrm{C}$ in a cryoprotectant solution ( $\mathrm{PB}$, glycerol, and ethylene glycol) until being processed for staining.

The antibodies against CCK and PV have been well characterized and are widely used. Sources, dilutions, and specificity references for the antibodies are presented in Table 1. To confirm specificity of labeling for each antibody, control experiments were performed in which slices were processed as follows: (1) without the primary antibody, (2) without the secondary antibody, or (3) after pretreatment with preabsorbed immune serum. Selective immunoreactivity, resembling that obtained with the specific antibodies, was not visible under any of these conditions for any of the targets of interest (data not shown). Additionally, several specific primary antibodies to each target were compared (Table 1) and found to yield similar patterns of immunostaining for CCK and PV. In all cases, the distribution of CCK and PV staining somata corresponded to patterns of immunolabeling reported previously (Kosaka et al., 1985; Drake and Milner, 2002; Pawelzik et al., 2002), with PV somata found primarily in s. oriens and s. pyramidale, and CCK somata found primarily in s. radiatum, s. lacunosum-moleculare, and s. pyramidale.

Slices were washed in several changes of $0.01 \mathrm{M} \mathrm{PB}$ to remove the cryoprotectant solution. Then, they were treated in $1 \%$ sodium borohydride solution $\left(\mathrm{NaB}_{4}\right)$ in $0.1 \mathrm{M} \mathrm{PB}$ for 30 min. The excess $\mathrm{NaB}_{4}$ was washed off with several changes of $0.1 \mathrm{M} \mathrm{PB}$, and slices were transferred into $0.02 \mathrm{M}$ potassium-PBS (KPBS) with normal blocking sera (normal goat serum and normal horse serum, 1:100) and $0.03 \%$ Triton-X. Slices were incubated overnight at room temperature, followed by incubation for $24-48 \mathrm{~h}$ at $4^{\circ} \mathrm{C}$ in a mixture containing both CCK and PV primary antibodies in $0.02 \mathrm{M}$ KPBS. After incubation, the sections were washed in KPBS (several changes over $30 \mathrm{~min}$ ) and then incubated in a mixture of fluorescent-tagged secondary antibodies and avidin macromolecules at room temperature in the dark for $30 \mathrm{~min}$. The mixture contained Cy5conjugated goat anti-rabbit IgG (diluted 1:200; Jackson ImmunoResearch Laboratories), fluorescein isothiocyanate (FITC)-conjugated horse anti-mouse IgG (diluted 1:400; Vector Laboratories), and avidin conjugated to Texas Red (diluted 1:400; Vector Laboratories). After incubation in the fluorochrome mixture, slices were extensively washed in 

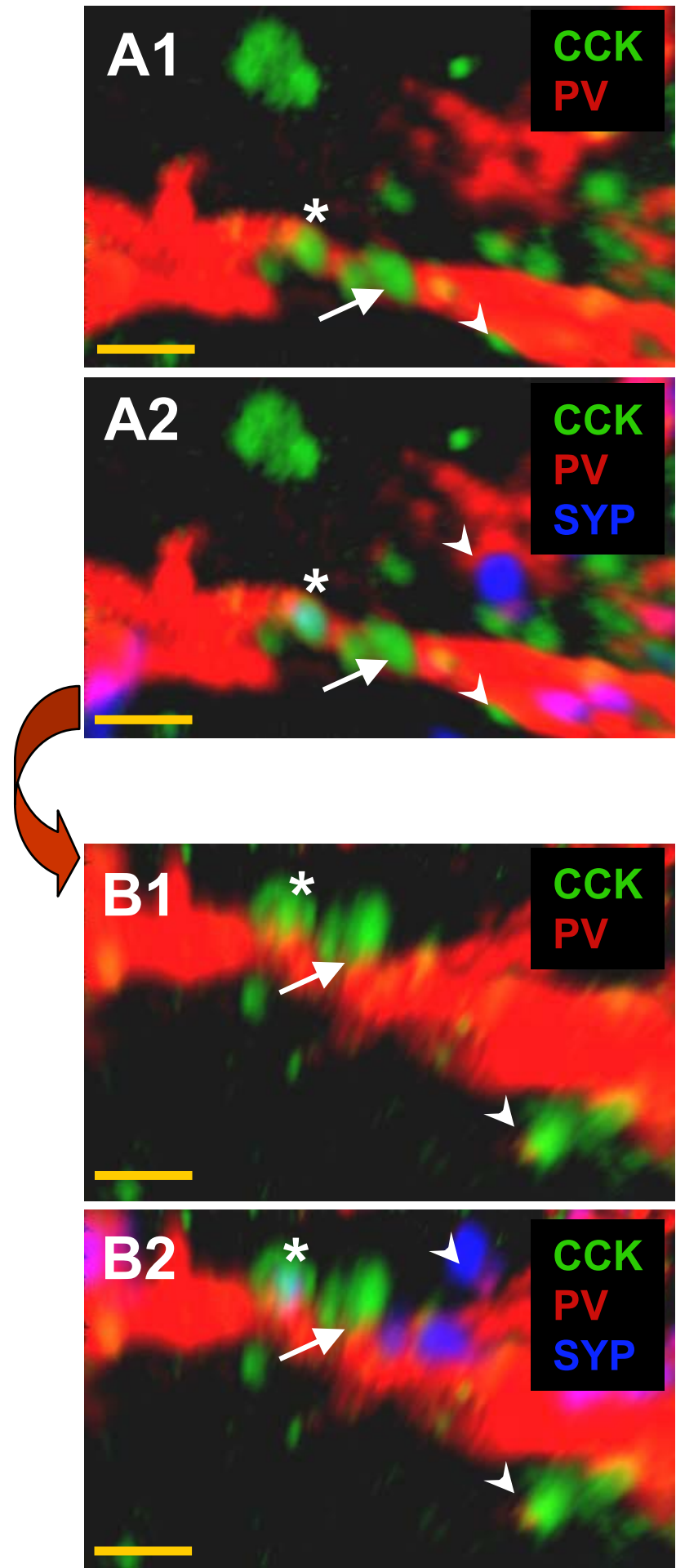

Figure 1. Examples of relationships between (CK-and PV-immunostained elements. $\boldsymbol{A 1}$, Several CCKterminals (green) appear adjacent to a PV (red) dendritic process. $\mathbf{A 2}$, Same field as $\boldsymbol{A} \boldsymbol{1}$ but including synaptophysin (SYP) staining (blue) reveals several SYP puncta, including one that completely colocalizes with a CCK terminal (asterisk). $\mathbf{B}$ and $\mathbf{B 2}$ show the same field as in $\boldsymbol{A}$ but after rotation $\left(90^{\circ}\right.$ into the plane of the image) revealing the putative synapse, close appositions (e.g., arrow), and nonassociations (e.g., arrowheads) between the PV- and CCK-stained elements. A close apposition was defined as two elements staining for CCK or PV that were contiguous within the limits of our optical resolution even when rotated. A putative synapse was defined as a close apposition in which the terminal was also SYP immunoreactive. Nonassociated elements did not remain in close apposition after image rotation. Note the $90^{\circ}$ rotation is used only for illustrative purposes; all images were in fact rotated through $360^{\circ}$ to confirm close apposition, as shown in the supplemental movie and supplemental Figure 1 (available at www.jneurosci.org as supplemental material). Magnification, $100 \times$. Scale bar, $1 \mu \mathrm{m}$.
KPBS (in the dark) and mounted onto glass slides in fluorescent mounting media (BIOFX Laboratories).

The slides were imaged using a Nikon microscope (Eclipse 80i) equipped with an OptiGrid structured light device (Qioptiq Imaging Solutions) and operated as part of a Volocity Grid Confocal system (Improvision). Fluorescence was examined using the following wavelengths: FITC excitation at $495 \mathrm{~nm}$, emission at $515 \mathrm{~nm}$; TRITC (tetramethylrhodamine isothiocyanate) (and Cy3) excitation at $555 \mathrm{~nm}$, emission at 605 $\mathrm{nm}$; and Cy5 excitation at $645 \mathrm{~nm}$, emission at $705 \mathrm{~nm}$. Z-stacks of individual channels were captured with a monochrome CCD camera (Hamamatsu ORCA ER) and colors were applied using Volocity software (Improvision). Individual channels and the combined images are presented. The somata of biocytin-loaded cells were located by scanning the slides at $20 \times$. On detection, a detailed study was performed at $100 \times$.

For axon tracing (see Fig. 6), after immunofluorescence evaluation, the sections were unmounted in $0.02 \mathrm{M}$ KPBS. After thorough washes in KPBS, the slices were put in avidin-biotinylated HRP complex (ABC Elite; Vector Laboratories) overnight; the biotin-labeled cells were subsequently revealed using a peroxidase reaction with diaminobenzidine (DAB) $(0.05 \%)$ as the chromagen and $0.015 \% \mathrm{H}_{2} \mathrm{O}_{2}$ as substrate. The $\mathrm{DAB}$ staining was enhanced with $0.5 \%$ nickel chloride. The sections were then dehydrated in an ascending ethanol series followed by xylene and then permanently mounted and coverslipped with Permount (Thermo Fisher Scientific). The recovered neurons, their dendrites and axonal arborizations were initially reconstructed and drawn using a camera lucida. For most axonal reconstructions, a different procedure was used: the labeled neurons were digitally photographed under a $100 \times$ objective, and the serial digital images were aligned in Adobe Photoshop CS4 (Adobe Systems), creating two-dimensional montages of the threedimensional projection. These montages were traced using Adobe Illustrator CS4 (Adobe Systems). This method is very efficient for reconstructing complex axonal arbors and is suitable for addressing questions in which information about the three-dimensional volume filled by the processes is not required.

Triple immunofluoresence. For triple-labeling experiments with CCK, PV, and synaptophysin (SYP) (for details, see Table 1), the procedure was similar to that discussed above, except for the tissue preparation. Rats were deeply anesthetized with sodium pentobarbital $(150 \mathrm{mg} / \mathrm{kg}$, i.p.) and subsequently perfused through the ascending aorta with $4 \%$ paraformaldehyde in PBS. The brains were removed and postfixed at room temperature for $1 \mathrm{~h}$ with $4 \%$ PFA. The tissue was then immersed in $30 \%$ sucrose overnight and $50-\mu \mathrm{m}$-thick coronal slices were made on a cryostat (Leica; CM3050S). In addition to the primary antibodies noted above, mouse anti-synaptophysin IgM was added to the primary antibody mixture, and the secondary antibody mixture contained 1:400 dilutions of anti-mouse IgM conjugated to Cy3, anti-mouse IgG conjugated to $\mathrm{Cy} 5$, and a biotinylated anti-rabbit IgG (Jackson ImmunoResearch Laboratories). This secondary mixture was followed by a quick rinse in KPBS and then $1 \mathrm{~h}$ at room temperature of 1:400 streptavidin conjugated to Cy2 (Jackson ImmunoResearch Laboratories) in KPBS.

The Volocity software collects $z$-stacks from multiple channels, but also converts these $z$-stack images into a single three-dimensional volume that can be rotated and further magnified, and each color channel can be independently monitored (supplemental movie, available at www. jneurosci.org as supplemental material). Three-dimensional volumes containing PV, CCK, and SYP immunoreactivity were created from $100 \times$ magnification. The image frame size was $1024 \times 1024$ pixels. Volumes for each image stack were $8 \mu \mathrm{m}$ thick. The step size was $0.2 \mu \mathrm{m}$ in depth (to minimize photobleaching), which resulted in volumes comprising $41 z$-sections with a voxel dimension of $0.07 \times 0.07 \times 0.2 \mu \mathrm{m}(x$, $y, z$, respectively). Exposure times were set using the Volocity "auto exposure" function for each channel. Noise was removed using a $3 \times 3 \times 3$ median filter. The mean background intensity was calculated for each volume. Objects were counted only if at least five times brighter than the background, and at least 4 voxels in size. Within the area of interest from these volumes, PV and CCK immunoreactive elements that appeared adjacent to one another were identified, measured, and their $x, y, z$ coordinates were recorded and numbered. When PV and CCK immunoreac- 

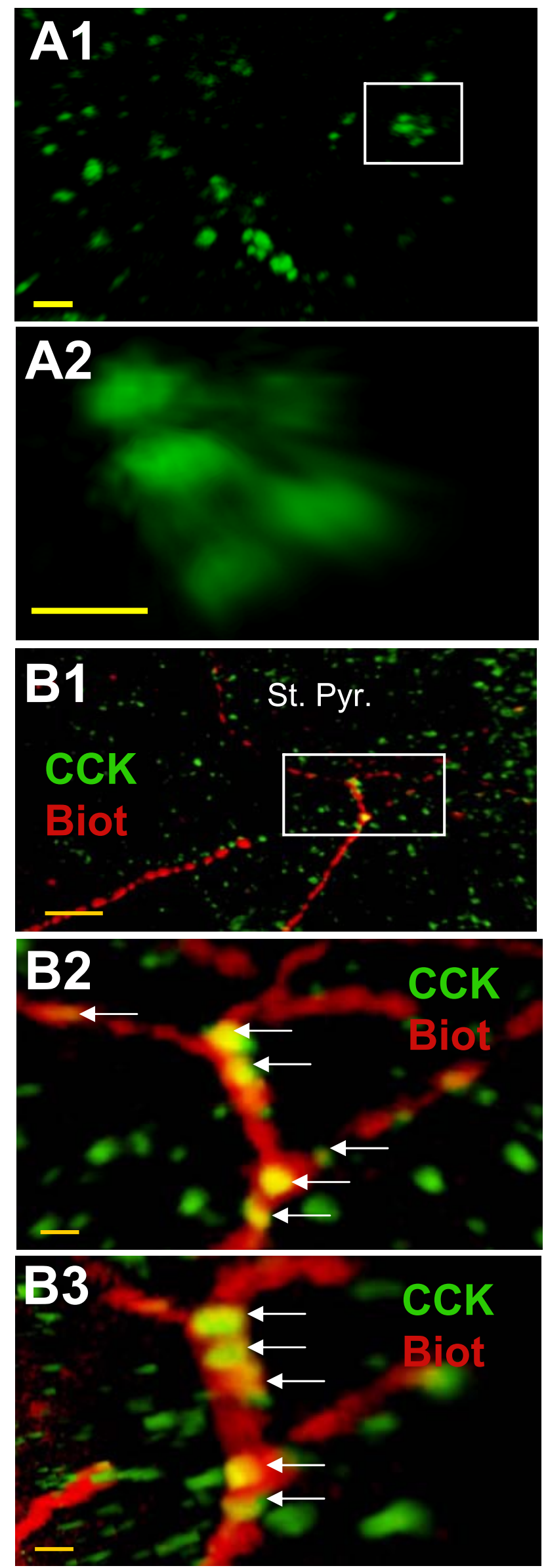

tivity was observed in adjacent pixels, the volume was rotated $360^{\circ}$ around several axes to determine whether or not these pixels were touching within a single optical plane. At $100 \times$ magnification, the pixel dimension is $\sim 70 \mathrm{~nm}$, which is therefore the limit of resolution of our confocal images. When the labeled pixels were touching, these were considered "close appositions" and were marked for additional analysis. After all PV and CCK close appositions within an area of interest were identified, the color channel including SYP immunoreactivity (Cy5) was added back to the volume, to determine whether either element within close apposition was also SYP-immunoreactive. The volumes were again rotated to insure that the SYP was colocalized with immunoreactivity to CCK or PV.

Electron microscopy and immunocytochemistry. Rats were deeply anesthetized with sodium pentobarbital $(150 \mathrm{mg} / \mathrm{kg}$, i.p.) and subsequently perfused through the ascending aorta with solutions of $10-15 \mathrm{ml}$ of saline $(0.9 \%)$ containing $1000 \mathrm{U}$ of heparin followed by $50 \mathrm{ml}$ of $3.75 \%$ acrolein and $2 \%$ paraformaldehyde in $0.1 \mathrm{M} \mathrm{PB}, \mathrm{pH} 7.4$. The brains were removed from the skull, cut into 5-mm-thick coronal blocks, and postfixed with $2 \%$ PFA in PB for 30 min. The block was cut into $40-\mu \mathrm{m}$-thick coronal sections on a Vibratome (Leica). The sections were collected serially in $\mathrm{PB}$ and treated with $1 \% \mathrm{NaB}_{4}$ in $\mathrm{PB}$ for 30 min before immunocytochemical labeling.

To enhance reagent penetration, sections were freeze-thawed. The tissue was placed into a container with a mesh bottom that then was placed into a cryoprotectant solution (30\% sucrose and 30\% ethylene glycol in $\mathrm{PB})$. The container was immersed in rapid succession in liquid Freon, liquid nitrogen, and PB. The tissue was then rinsed in $0.1 \mathrm{M}$ Tris-saline (TS), and then incubated in $0.5 \%$ bovine serum albumin (BSA) in $0.1 \mathrm{M}$ TS for 30 min to block nonspecific binding.

A combination of the primary antibodies to CCK and PV was prepared in TS with $0.1 \% \mathrm{BSA}$ and incubated at $4^{\circ} \mathrm{C}$ for $48 \mathrm{~h}$. After incubation, the slices were rinsed in $0.1 \mathrm{M} \mathrm{TS}$, and then placed in a biotinylated secondary antibody (goat anti-rabbit; Jackson ImmunoResearch Laboratories) at $1: 400$ in TS with $0.1 \%$ BSA for $30 \mathrm{~min}$ at room temperature. CCK was detected according to the avidin-biotin complex (ABC) procedure by incubating the slices in a peroxidase-avidin complex (Vectastain Elite; Vector Laboratories) for $30 \mathrm{~min}$ according to the manufacturer's instructions. Finally, the slices were placed in diaminobenzidine (SigmaAldrich) and $\mathrm{H}_{2} \mathrm{O}_{2}$ for $6 \mathrm{~min}$, and then washed in $0.1 \mathrm{M} \mathrm{PB}$. They were examined under a light microscope to determine appropriate staining. Subsequently, they were incubated in gold anti-mouse IgG $(1 \mathrm{~nm}$ gold particles; Electron Microscopy Sciences) at 1:50 in PB to reveal PV staining. After washing in $0.01 \mathrm{M}$ PBS, slices were placed in $2 \%$ glutaraldehyde for $10 \mathrm{~min}$, followed by washes in PBS and then $0.2 \mathrm{M}$ citrate buffer. Finally, slices were treated with a silver intensification solution (IntenSE silver enhancement; GE Healthcare) for $6 \mathrm{~min}$, washed in citrate buffer, and finally in $\mathrm{PB}$. To verify labeling, we also performed the reverse procedure, detecting CCK with gold particles and PV with DAB.

The PB was drawn off and replaced with $2 \%$ osmium tetroxide for $1 \mathrm{~h}$, and then dehydrated through an ascending series of ethanol rinses ( $5 \mathrm{~min}$ each; 30, 50, 70, 95, and 100\%; times two), followed by $20 \mathrm{~min}$ in propylene oxide. Next, slices were rotated overnight in EMBed 812 and propylene oxide, followed by $2 \mathrm{~h}$ in pure EMBed 812. Sections were embedded in EMbed 812 (Electron Microscopy Sciences) between two sheets of Aclar plastic (Milner et al., 2001). Sections through the CA1 region of the dorsal hippocampus were glued onto Epon chucks and trimmed to a $1 \mathrm{~mm}$ trapezoid. Ultrathin sections ( $\sim 75 \mathrm{~nm}$ thick) were

Figure 2. Punctate CCK immunoreactivity. CCK immunoreactivity frequently appeared as clusters of three to six puncta each $250-300 \mathrm{~nm}$ in diameter. $\boldsymbol{A}$, Image depicting several CCK clusters observed within s. pyramidale. Scale bar, $1 \mu \mathrm{m}$. $\boldsymbol{A}$, Enlarged view of a cluster from $\boldsymbol{A} \mathbf{1}$. Images were taken at $100 \times$. Scale bar, $250 \mathrm{~nm}$. B, CCK puncta are present in preterminal axons. $B 1$, Low-power image of s. pyramidale, showing CCK immunostaining in green, and the biocytin-filled axon from a CCK interneuron making close contacts with the large dark spaces that represent pyramidal cell somata. $\boldsymbol{B} \mathbf{2}$ and $\boldsymbol{B} \mathbf{3}$ are higher-power images of the area outlined by the white box in $\boldsymbol{B} 1 ; \boldsymbol{B} 3$ is a $90^{\circ}$ rotation of the image in $\boldsymbol{B} 2$, showing that the CCK puncta are present within the axon (yellow puncta). Scale bars: $\boldsymbol{B} 1,10 \mu \mathrm{m} ; \boldsymbol{B 2}, \boldsymbol{B} \mathbf{B}, 1 \mu \mathrm{m}$. 
cut through the hippocampal CA1 region on a Leica Ultracut ultratome, collected into copper mesh grids, and counterstained with 5\% uranyl acetate and Reynolds lead citrate as described previously (Milner et al., 2001). Final preparations were analyzed on a FEI Tecnai Biotwin electron microscope equipped with a digital camera (Advanced Microscopy Techniques, software version 3.2).

Immunoreactive processes were identified using the criteria of Peters et al. (1991). Perikarya were identified by the presence of a nucleus. Dendrites contained regular microtubular arrays and were usually postsynaptic to axon terminal profiles. Terminal profiles had minimal diameters $>0.2 \mu \mathrm{m}$, contained numerous small synaptic vesicles, and often contacted other neuronal profiles. The term "contact" is used here to include asymmetric and symmetric synapses as well as close appositions. Asymmetric synapses had thick postsynaptic densities, whereas symmetric synapses exhibited narrower synaptic densities. Appositions were defined as contacts not separated by glial profiles but lacking intercleft material or conventional synapses in the plane of section analyzed.

\section{Results}

Immunocytochemical evidence of axosomatic, axodendritic, and axoaxonic $\mathrm{CCK} \rightarrow \mathrm{PV}$ synapses

If our working hypothesis is correct, there should be both morphological and physiological evidence for synapses between CCK and PV neurons. Accordingly, we began by immunostaining rat hippocampal slices for CCK and PV and examining the CA1 pyramidal cell perisomatic regions (i.e., neuropil in s. pyramidale and proximal s. radiatum out to $\sim 50 \mu \mathrm{m}$ from the s. pyramidale border) under confocal fluorescence microscopy, looking for close appositions between elements of the two cell types. A close apposition was defined as staining for CCK and PV that was essentially touching, within the limits of our optical resolution (i.e., labeling present in adjacent pixels) (pixel dimension, $\sim 70$ $\mathrm{nm}$ ). We observed numerous kinds of close appositions between axonal branches of one of the cell types and elements of the other cell type (Fig. 1). To ensure that close appositions were not the result of chance superposition of elements in different $z$-planes, the sections were optically sectioned throughout along the $z$-axis and then reassembled in software (see Materials and Methods). Optical reconstruction permitted rotation of the sections in three dimensions and rejection of apparent appositions that did not remain close when examined from all sides (Fig. 1A2,B2; supplemental Fig. 1 and supplemental movie, available at www.jneurosci.org as supplemental material).

In six slices from five rats, we randomly selected $58 \mathrm{CCK}$ or PV cells with somata located within s. pyramidale and assessed a total of 1093 apparent contacts (476 PV terminals near CCK somata and 563 CCK terminals near PV somata). Close appositions were formed in equal proportions by CCK onto PV somata (349 of 563 or $62 \%$ ) and by PV terminals onto CCK somata (301 of 476 or $63 \%$ ); the remaining 343 apparent contacts did not meet the criteria for close appositions when subjected to three-dimensional rotation and were rejected from additional analysis. Because basket cell axons innervate s. pyramidale in uniquely high density (Freund and Buzsáki, 1996) (see Fig. 7), it is likely that the large majority of labeled axons in this region are from CCK or PV basket cells, although a minor contribution from other subtypes could not be entirely ruled out.

CCK terminals were relatively easy to identify, as CCK staining is punctate and restricted to small spheres $\sim 250-300 \mathrm{~nm}$ in diameter (Fig. 2A). Sometimes, as illustrated in Figure 2, CCK immunoreactivity revealed clusters of three to six spheres, but frequently only one was present in a single apparent axon terminal branch (Fig. 1A). CCK is obviously not free to diffuse throughout the cytoplasm and exists in discrete puncta even in preterminal axons (Fig. $2 \mathrm{~B}$ ). Although the nature of the CCK puncta is unknown, they could be organelles, possibly dense-core vesicles. Despite being found in and near synaptic terminals, CCK puncta were not unique markers for synapses (see below). As PV is diffusely present in PV cells, the PV terminal and preterminal regions were continuously labeled.

To determine whether the apparent close appositions between axonal terminals and somata indeed represented synapses, we simultaneously evaluated immunostaining for the presynaptic marker SYP together with that of CCK and PV (Fig. 3). Once CCK and PV elements were identified as forming a close apposition, we activated the SYP color channel and determined whether there was extensive colocalization between CCK or PV and SYP. To insure that the different labels were actually colocalized, we also examined these putative synapses with three-dimensional rotation and evaluated each label in the field individually and in combination with the others (supplemental Fig. 1 and supplemental movie, available at www.jneurosci.org as supplemental material). We initially focused exclusively on the somatic region of the cell, excluding any process extending from what would clearly be considered soma. As shown in Figure 3 and summarized in Table 2, SYP labeling was present within (i.e., not merely juxtaposed to) many of the close appositions between CCK or PV processes onto the somatic regions of the other type of cell. Most (59.0\%) of the close appositions between CCK processes and PV somata were SYP immunoreactive, whereas significantly fewer (34.2\%) of the close appositions between PV processes and CCK somata were SYP immunoreactive. As SYP labeling is distinctive for synapses, we infer that close appositions in which another marker is coextensive with SYP labeling represent synapses, and a process labeled for SYP is a synaptic terminal. By dividing the total number of cell somata examined by the total number of putative synapses onto the cells, it is possible to estimate that, on average, a PV soma received seven CCK synapses, whereas a CCK soma received four PV synapses (Table 2).

To investigate possible axodendritic synapses, we repeated the triple immunofluorescence analysis on perisomatic dendrites. The somatic-dendritic boundary can be difficult to identify, so we conservatively defined a dendrite as beginning $20 \mu \mathrm{m}$ distal to the apparent projected boundaries of the soma. We focused on perisomatic dendrites because we could trace their connection to the soma, and thus ensure that they came from a likely basket cell, whereas dendrites in the neuropil of s. radiatum can be much more difficult to associate with a cell of origin. Axodendritic synapses were counted in fixed volumes $(10 \times 3 \times 1.6 \mu \mathrm{m})$ from each of 30 cells. Morphologically defined dendritic synapses occurred with an average density of $\sim 1$ per $48 \mu \mathrm{m}^{3}$ of proximal dendrite examined. This method only establishes that the perisomatic synapses exist and does not permit an accurate quantitative estimate of the numbers of synapses outside the analyzed regions. Details are given in Table 2.

The previous results provide evidence of axosomatic and axodendritic $\mathrm{CCK} \rightarrow \mathrm{PV}$ synapses. We also considered the possibility of axoaxonic coupling between the CCK and PV interneurons by examining nine different regions $(10 \times 10 \times 4 \mu \mathrm{m})$ in CA1 s. pyramidale in each of five rats ( 45 regions total). The regions were selected such that they did not include CCK or PV somata (but were otherwise chosen randomly) and appeared to include mainly axonal processes of the two interneuron subtypes. In all, we counted 3389 CCK and PV potential contacts, and, of these, 442 were part of close appositions between CCK and PV, and 299 were in putative synapses (i.e., close appositions colocalized with SYP) (Fig. 4) (for details, see Table 2). There were about twice as many CCK terminals onto PV axons (184), as PV terminals onto 

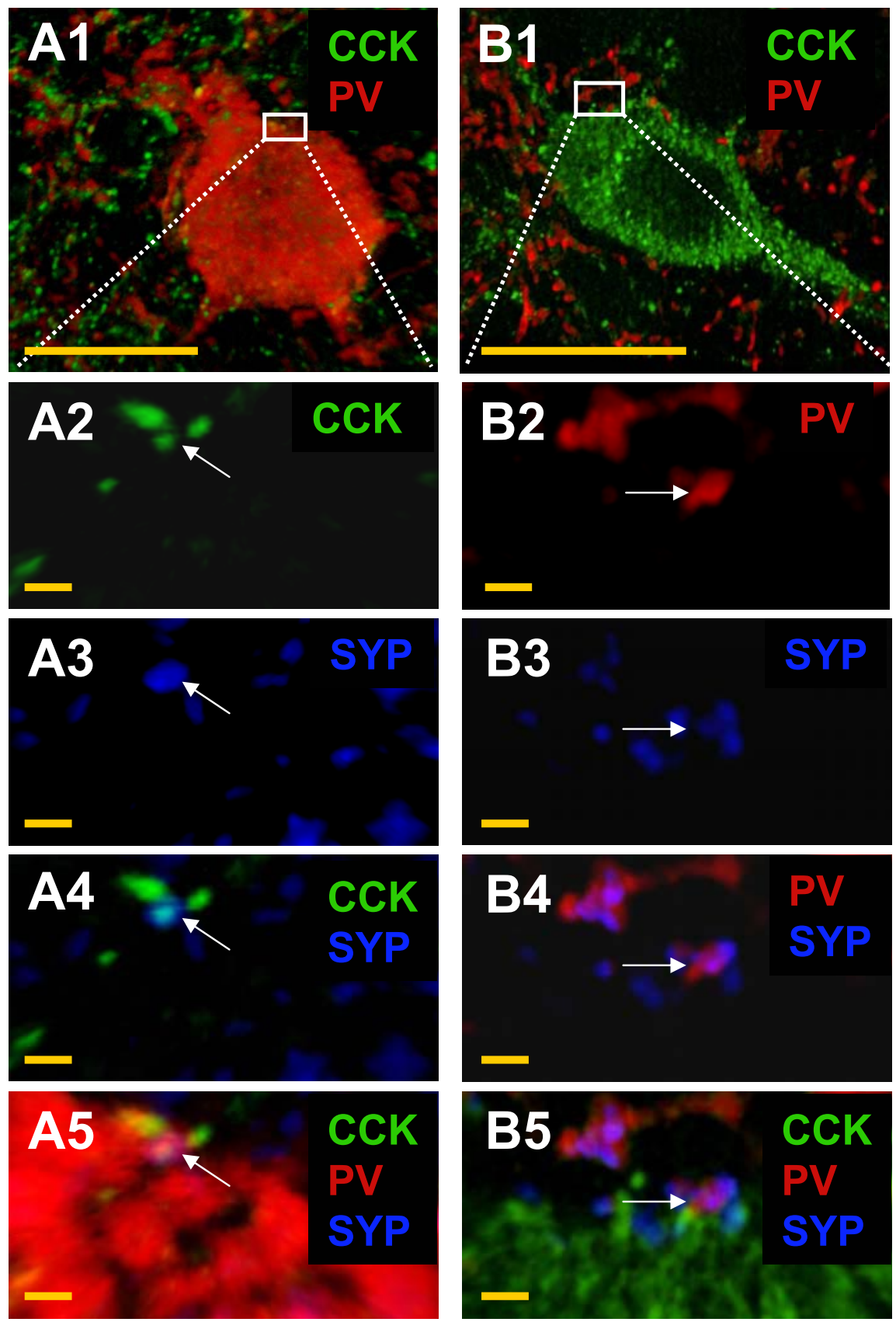

Figure 3. Axosomatic synapses between CCK and PV interneurons in CA1 s. pyramidale. A1, A PV interneuron (red) is surrounded by many CCK-immunoreactive (green) terminals. A2-A5, Magnified images of the region of interest demarked by the box in $\boldsymbol{A 1}$. A2, Several CCK terminals are observed within the region of interest. A3, SYP immunoreactivity (blue) is also observed. A4, Colocalization of a CCK terminal and SYP (arrow). A5, The CCK/SYP immunoreactive terminal is in close apposition to the PV soma forming a putative synapse. Similarly, in $\boldsymbol{B} \mathbf{1}$, a CCK interneuron (granular appearance because of numerous (CK puncta) is surrounded by many PV-immunoreactive terminals. $B 2-B 5$ show a magnified image of the region of interest demarked by the box in $\boldsymbol{B 1}$. B2, Several PV terminals are present within the region of interest. $\boldsymbol{B}$ 3, SYP immunoreactivity is also observed. $\boldsymbol{B}$, Colocalization of a PV terminal and SYP (arrow). B5, The PV/SYP-immunoreactive terminal is in close apposition to the PV soma. Images were taken at $100 \times$. Scale bars: $\mathbf{A} \mathbf{1}, \mathbf{B} \mathbf{1}, 15 \mu \mathrm{m}$; all other panels, $1 \mu \mathrm{m}$.

CCK axons (84). In the 31 remaining cases, the SYP labeling was so extensively colocalized with both CCK and PV labeling that a unique presynaptic element could not be identified. Conceivably, these could be instances in which the SYP was actually localized in one terminal but the staining was too diffuse to determine which terminal it was, or they could be actual contacts between true synaptic terminals of both axons. As in the axosomatic material, the apparent axoaxonic $\mathrm{CCK} \rightarrow \mathrm{PV}$ cell synapses are more nu- merous in a given area than the reverse pattern (paired $t$ test, $p<0.0001$ ).

The CCK puncta are not unique markers for synapses, as can be seen by the dense proliferation of puncta throughout the CCK somatic cytoplasm (Fig. 3B1). The numerous instances of CCK puncta not associated with SYP (Figs. 1, 3) could represent storage or transit of CCK organelles within CCK neuronal processes. To estimate the degree of association of CCK puncta with probable synapses (i.e., the percentage of puncta in which CCK and SYP labeling was coextensive), we counted all CCK puncta within the regions analyzed in the previous paragraph. We excluded puncta within CCK somata and proximal densely filled processes, as well as those with faint, nonspherical shapes that were apparently not fully contained within the search region. In these regions, we identified a total of 3054 CCK puncta, and, of these, $498(16.3 \%)$ were coextensive with SYP labeling, that is, apparently part of some type of synapse; hence the great majority of CCK puncta were not obviously associated with synapses. It is interesting that of the 498 apparent CCK synapses within these s. pyramidale regions, 184 (37\%) were made onto PV-labeled processes.

The data thus far are consistent with the hypothesis of synaptic contacts between CCK and PV cells. As communication between these two prominent and widely distributed interneuronal types has not previously been reported, we examined the tissue ultrastructurally with dual-immunolabeling methods and performed paired-cell electrophysiological recordings.

\section{Ultrastructural evidence of $\mathrm{CCK} \rightarrow$ PV synapses}

As a direct morphological test of the hypothesis, we stained slices for CCK and PV (antibodies labeled with immunogold particles or DAB) (see Materials and Methods) and then examined ultrathin sections of CA1 tissue from s. pyramidale, s. radiatum, and s. oriens under EM. At the EM level, CCK-labeled terminals could be readily identified synapsing on PV-labeled somata and dendrites, and vice versa. Although we did not do a quantitative stereological analysis, we examined 48 regions from CA1 of two rats. These regions, which contained both CCK and PV immunoreactivity, were randomly selected from within six grid squares (three squares from each rat). The grid squares were chosen to include one each from s. pyramidale, s. radiatum, and s. oriens, with the squares from s. radiatum and s. oriens proximate to s. pyramidale. The area sampled included six squares at $3025 \mu \mathrm{m}^{2}$ per square, or a total of $18,150 \mu \mathrm{m}^{2}$. In all, there were 152 CCK or PV 
Table 2. Close appositions (appos.) ${ }^{a}$ and putative synapses ${ }^{b}$ identified by three-dimensional confocal imaging of fluorescence antibody labeling of CCK, PV, and SYP in CA1 s. pyramidale

\begin{tabular}{|c|c|c|c|c|c|c|c|}
\hline $\begin{array}{l}\text { Precontact } \\
\text { process }\end{array}$ & $\begin{array}{l}\text { Postcontact } \\
\text { element }\end{array}$ & Cells $(n)$ & $\begin{array}{l}\text { Apparent contacts } \\
(n)^{c}\end{array}$ & Close appos. $(n)$ & $\begin{array}{l}\text { Putative synapses } \\
\text { (n) }\end{array}$ & $\begin{array}{l}\text { Putative synapses/ } \\
\text { close appos. }(\%)\end{array}$ & $\begin{array}{l}\text { Putative synapses/ } \\
\text { ROI }^{d} \text { (estimated) }\end{array}$ \\
\hline & SOMA & & 1093 & & & & \\
\hline CCK & PV & 31 & & 349 & 206 & $59.0^{* * *}$ & 7 \\
\hline \multirow[t]{2}{*}{ PV } & $\mathrm{CCK}$ & 27 & & 301 & 103 & 34.2 & 4 \\
\hline & DEND $^{e}$ & & 730 & & & & \\
\hline CCK & PV & 15 & & 83 & 19 & $22.9^{* * *}$ & $>1$ \\
\hline \multirow[t]{2}{*}{ PV } & CCK & 15 & & 102 & 8 & 7.8 & $<1$ \\
\hline & AXON & & 3389 & & & & \\
\hline CCK & PV & & & 1585 & 184 & $11.6^{* * *}$ & n.d. ${ }^{f}$ \\
\hline PV & CCK & & & 1804 & 84 & 4.6 & n.d. ${ }^{f}$ \\
\hline n.d. ${ }^{g}$ & n.d. & & & & 31 & & n.d. ${ }^{f}$ \\
\hline
\end{tabular}

${ }^{a}$ Defined as labeling for CCK and PV in contiguous pixels under three-dimensional rotation (pixel dimension, $\sim 70 \mathrm{~nm}$ ).

${ }^{b}$ Defined as labeling in a close apposition in which SYP labeling was coextensive with either CCK or PV labeling (i.e., SYP labeling was at least partly present in the same pixels).

'All apparent contacts were examined by three-dimensional rotation; those not meeting the definition of close apposition were ignored.

${ }^{d}$ ROl, Region of interest in each row [i.e., soma or dendritic volume as defined below (see footnote $e$ )].

e Standard volumes of proximal dendrites $\left(10 \times 3 \times 1.6 \mu \mathrm{m}=48 \mu \mathrm{m}^{3}\right)$ were measured. DEND, Dendrite.

'Discontinuous punctate CCK labeling and complex arborization precluded estimation of the number of synapses made onto a given axon or cell.

${ }^{g}$ Substantial overlap of labeling for all three (CCK, PV, and SYP) prevented determination of which was the "precontact" process or whether both CCK and PV made synapses at these sites.

***Difference in this pair of values is significant at $p<0.0003$ ( $\chi^{2}$ test).

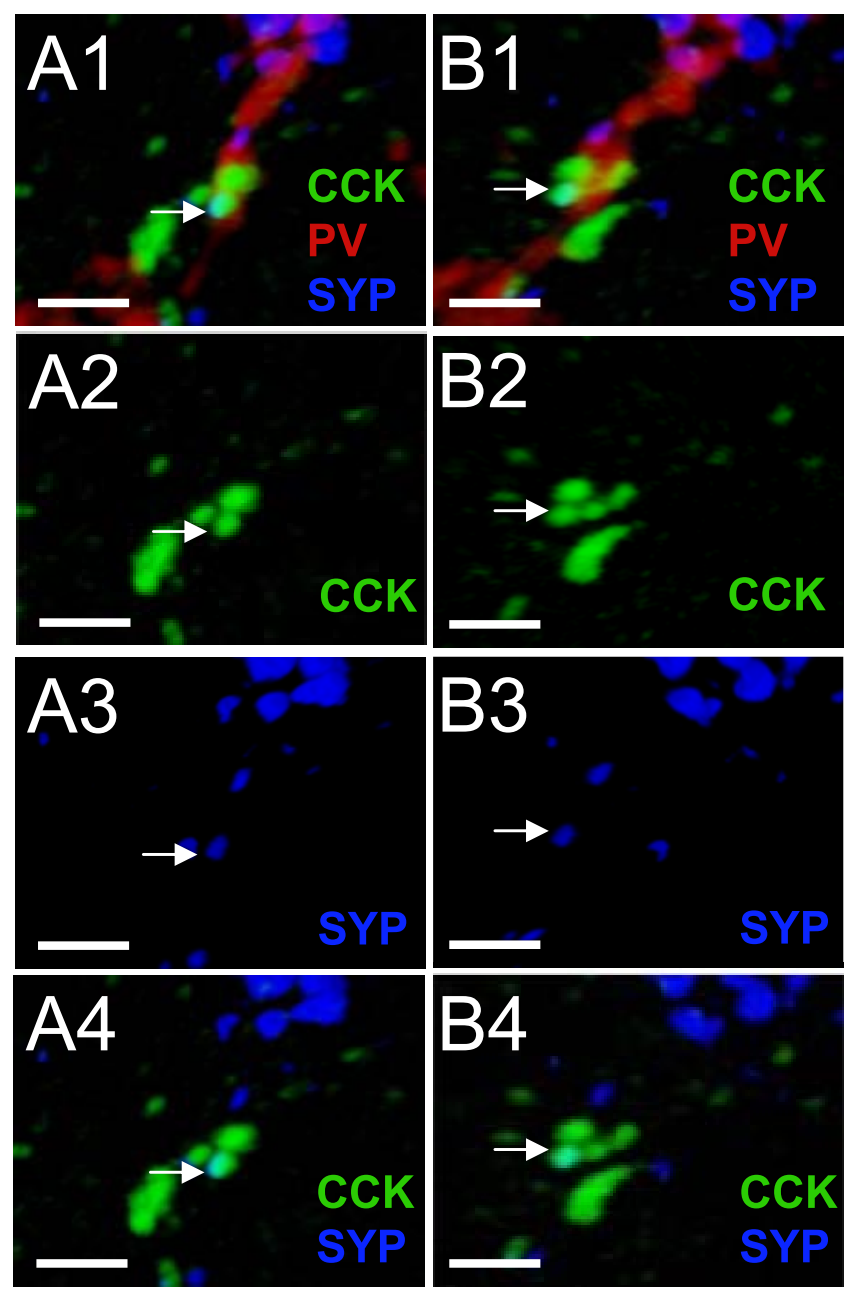

Figure 4. Axoaxonic contacts between CCK and PV interneurons in s. pyramidale. $A, A$ PV interneuron axon (red) is surrounded by many CCK-immunoreactive (green) terminals, and one terminal in close apposition is both CCK and SYP immunoreactive (blue). B1-B4, The $90^{\circ}$ counterclockwise rotations of $\boldsymbol{A} \mathbf{1}-\boldsymbol{A} 4$ showing that the cells remain contiguous. Scale bars, $1 \mu \mathrm{m}$. apparent terminals, of which 44 formed synapses, whereas 43 were present in close appositions not clearly synapses (the rest were not part of either configuration). Twenty-seven synapses were made onto pyramidal cells ( 14 by CCK terminals; 13 by PV terminals). The remaining 17 represented $\mathrm{CCK} \rightarrow \mathrm{PV}$ synapses (12), CCK $\rightarrow$ CCK synapses (3), or PV $\rightarrow$ CCK synapses (2). Examples are shown in Figure 5.

Whole-cell recordings from synaptically coupled pairs of cells The morphological data indicate that the anatomically defined chemical synapses between PV and CCK cells exist. To determine whether these synapses were functional, we performed dual whole-cell recording experiments followed by immunocytochemical labeling to identify the cells. Although axon terminals of both PV and CCK interneurons innervate closely apposed perisomatic sites of pyramidal cells, their somata are distributed differently. The CCK cells outnumber the PV cells in s. radiatum, whereas the PV cells are more abundant in s. pyramidale and s. oriens (Freund and Buzsáki, 1996; Pawelzik et al., 2002); therefore, we generally targeted one cell in each region. Perisomatic targeting interneurons tend to congregate near s. pyramidale, rather than more distally, and we therefore specifically recorded from cells near s. pyramidale. Electrodes included biocytin or Neurobiotin, and, after electrophysiological recordings, all slices were fixed and the biotin-loaded cells were identified as CCK- or PV-expressing as determined by immunocytochemistry.

In these initial tests, we looked for uIPSCs in 227 pairs of cells, and fixed slices for immunostaining if the cells had been found to be synaptically coupled, or other experimental procedures had been performed. We identified 43 recordings that included at least one CCK cell. Of the 43 pairs, 24 were synaptically coupled, although detailed physiological analysis was possible in only 22. Hence, we encountered synaptic coupling in 10.7\% (24 of 224) of the pairs, a rate comparable with that of previous reports (Glickfeld and Scanziani, 2006; Ali, 2007; Neu et al., 2007). Note that these totals only include pairs that were voltage-clamped for uIPSC study and do not include the 86 pairs we subsequently tested in current-clamp experiments (see below).

Of the 22 synaptically coupled pairs, we encountered different combinations with a CCK cell as the presynaptic partner [all pairings were unique (i.e., a given cell was a partner in only one 


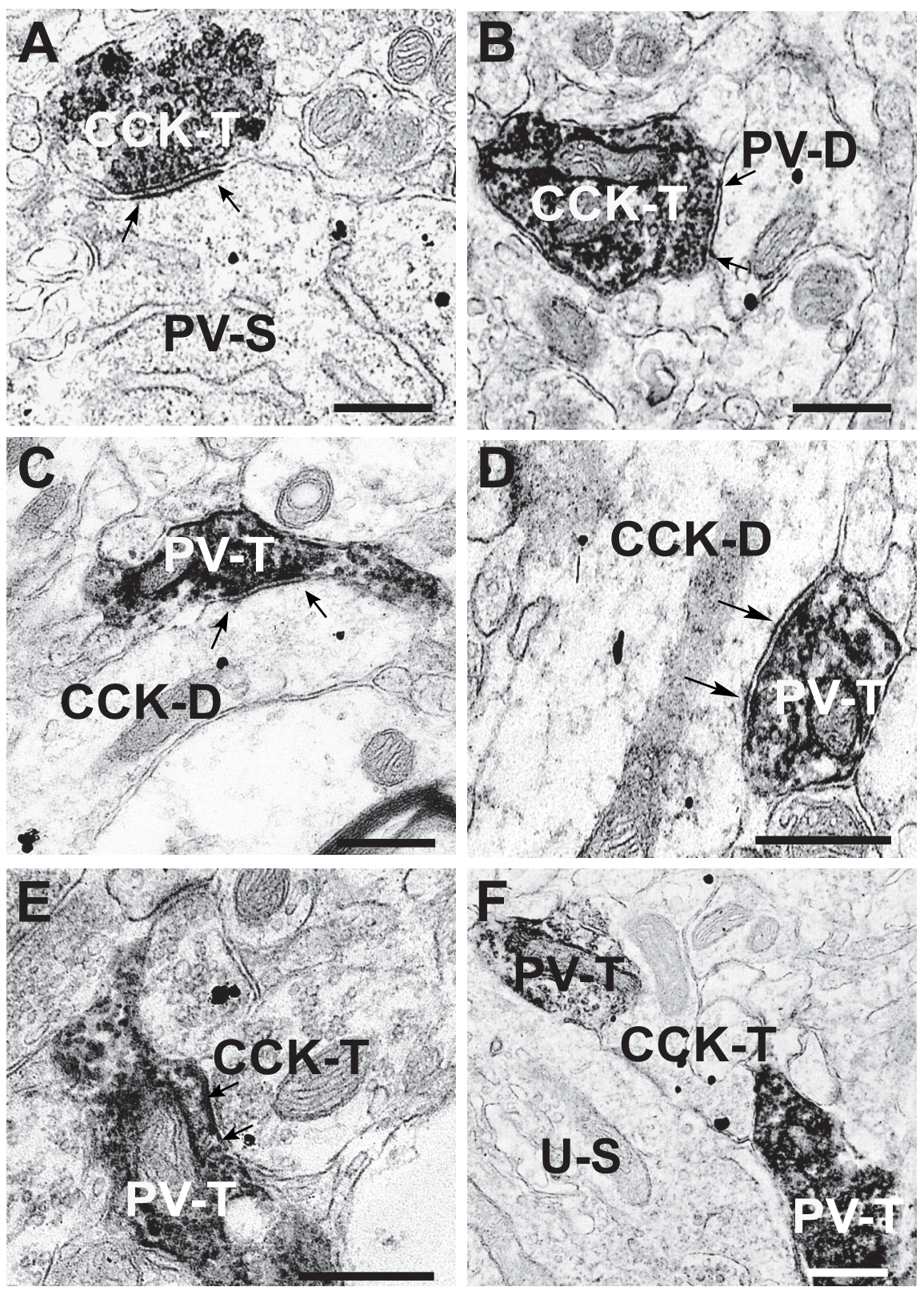

Figure 5. Electron micrographs of contacts between (CK- and PV-immunoreactive elements in hippocampal CA1 region. $A$, A CCK-labeled terminal (CCK-T) (developed with DAB) forms a synapse (between arrows in all panels) with a PV-labeled soma (PV-S) (silver-intensified gold particles). B, A CCK-labeled terminal (DAB) forms a synapse with a PV-labeled dendrite (gold). C, A PV-labeled terminal (DAB) forms a synapse with a CCK-labeled dendrite (gold). D, A PV-labeled terminal (DAB) contacts a CCK-labeled dendrite (gold). $\boldsymbol{E}$, A CCK-labeled terminal (gold) contacts a PV-labeled terminal (DAB). $\boldsymbol{F}$, Close appositions between PV (DAB) terminals and a CCK terminal (gold). An unlabeled, presumed pyramidal cell soma (U-S) is nearby. $\boldsymbol{A}$ and $\boldsymbol{B}$ were from s. oriens; $\boldsymbol{C} \boldsymbol{F}$ were from s. pyramidale. Scale bars, $500 \mathrm{~nm}$ (for all panels).
(2001)] (cf. Földy et al., 2006; Neu et al., 2007). We did observe DSI in the only $\mathrm{CCK} \rightarrow$ CCK basket cell pair tested [supporting the data of Ali (2007), who showed that Schaffer collateral-associated (SCA) CCK cells express DSI].

An example of a coupled $\mathrm{CCK} \rightarrow \mathrm{PV}$ pair is shown in Figure 6. Basic properties of the cells in synaptically coupled pairs are given in Table 3. Input resistances of CCK and PV cells were approximately three times higher than those of pyramidal cells. The probability of GABA transmission $\left(P_{r}\right)$ (calculated as the percentage of presynaptic action potentials that generated a uIPSC in the postsynaptic cell) was assessed with groups of five interneuronal action potentials induced by $3 \mathrm{~ms}$ DC pulses given at $10 \mathrm{~Hz}$ while recording the uIPSC simultaneously in the postsynaptic partner (50-195 presynaptic action potentials per pair). The CCK cell $P_{r}$ ranged from 0.37 to 0.96 in different pairs, but mean $P_{r}$ was very similar across all pairs. The uIPSCs were significantly larger $(\sim 80 \%)$ in CCK $\rightarrow$ PYR pairs, but essentially the same in the other two groups. All uIPSCs made by CCK cells had similar variable onset latencies. Interestingly, the paired-pulse ratio of CCK cell uIPSC transmission (mean $R_{2} /$ mean $R_{1}$ ) at $50 \mathrm{~ms}$ was the same for all postsynaptic cell types and nearly 1.0 across the pairs tested (mean, $1.07 \pm 0.14 ; n=10$ ), indicating that, on average, the CCK synapses neither strongly depress nor facilitate at this interval. Hence, electrophysiological data confirm that CCK cells make functional synaptic contacts with PV cells but that the contacts themselves do not have distinctive functional properties.

We observed that GABA release in $\mathrm{CCK} \rightarrow$ PYR pairs was reliable in 6 of 10 cases. In these pairs, uIPSCs were readily evoked by single action potentials, and $P_{r}$ was comparable with the $P_{r}$ when interneurons were postsynaptic (Table 3 ). In the four remaining $\mathrm{CCK} \rightarrow$ PYR pairs, there was essentially no release until repetitive pulses were given at $50 \mathrm{~Hz}$, and then the release was mostly asynchropair)]: CCK $\rightarrow$ PV (5 coupled among $13 \mathrm{CCK} \rightarrow \mathrm{PV}$ pairs), $\mathrm{CCK} \rightarrow \mathrm{CCK} \quad(7$ coupled among $14 \quad \mathrm{CCK} \rightarrow \mathrm{CCK}$ pairs), CCK $\rightarrow$ pyramidal (PYR) cell (10 coupled among 16 CCK $\rightarrow$ PYR pairs). We did not encounter reciprocally connected pairs of any combination, or presynaptic PV cells. Pyramidal cells were visually identified by their location in s. pyramidale, their size, shape, orientation, receipt of uIPSCs from identified cells, and absence of labeling by either CCK or PV antibodies. Although we did not investigate it in detail, we noted that eCB-mediated, depolarization-induced suppression of inhibition (DSI) (Alger, 2002) of uIPSCs was detectable in CCK $\rightarrow$ PYR pairs (data not shown), but not $\mathrm{CCK} \rightarrow \mathrm{PV}$ pairs [consistent with Wilson et al. nous. This issue is considered in more detail below.

Electrical synaptic coupling exists among CCK cells in neocortex (Galarreta et al., 2004), and the SCA-CCK cells of CA1 (Ali, 2007). Although we looked for evidence of electrical coupling in all chemically coupled pairs of cells, we did not detect it. Nevertheless, the gap junctions that mediate electrical signaling are very sensitive to various intracellular properties, such as $\mathrm{pH}$ and $\mathrm{Ca}$ (Spray and Bennett, 1985), and it is possible that a technical factor prevented our observation of electrical signaling. Alternatively, gap junctions among these cells could be electrotonically distant from the somata, and hence undetectable by our whole-cell pipettes. 

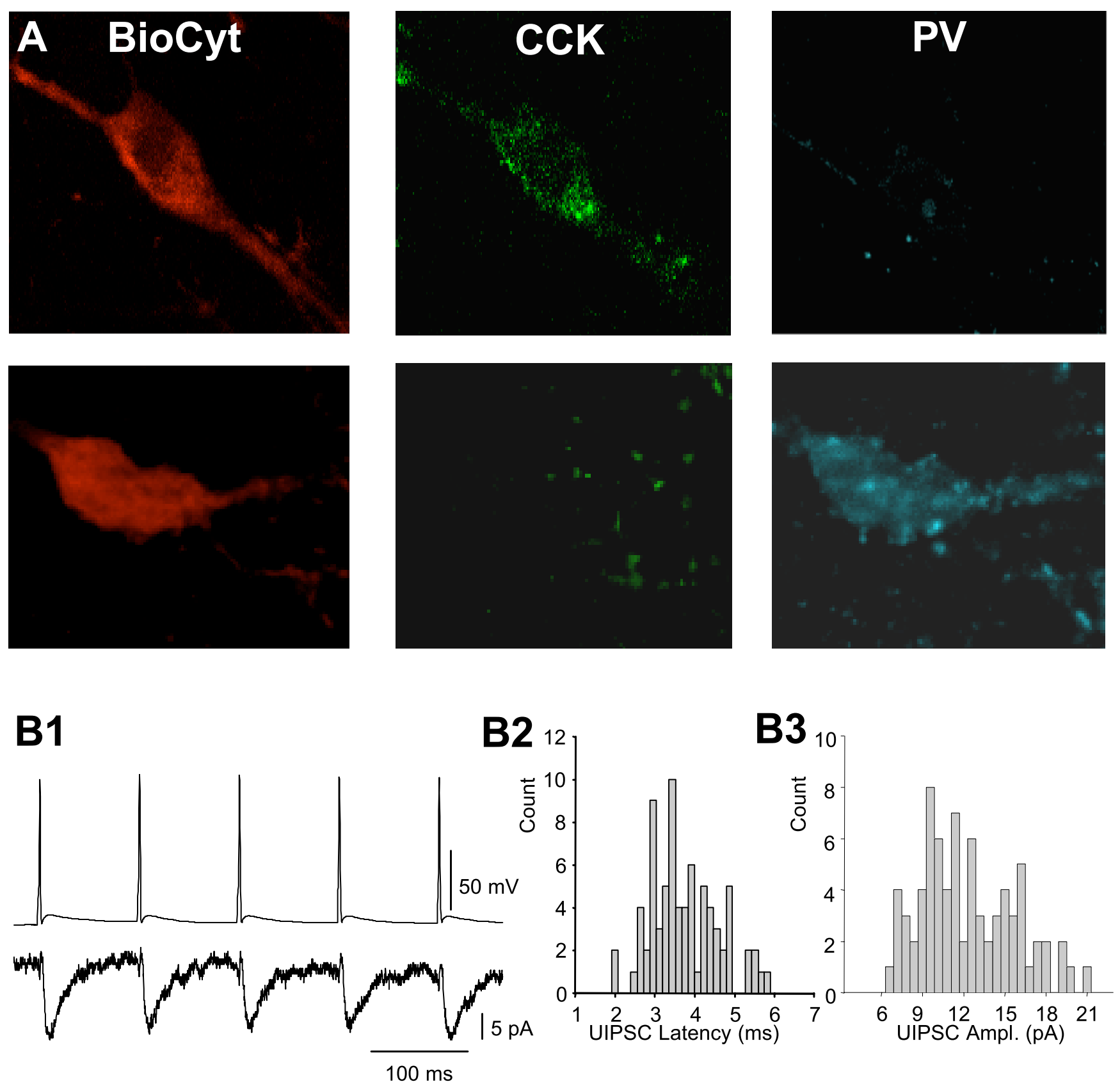

Figure 6. Synaptic transmission from CCK cell to PV cells. $A$, The two biocytin-labeled cells are shown in $A$ (left column), after the slice was immunostained for CCK (middle column) and PV (right column). $\boldsymbol{B} 1$ shows a train of five action potentials induced in the CCK cell at $10 \mathrm{~Hz}$ and simultaneously recorded ulPS(s in the postsynaptic PV cell (average of 41 trials). $\boldsymbol{B} 2$ and $\boldsymbol{B} 3$ represent histograms of 77 ulPSC latencies (B2) and amplitudes (B3) recorded from the same cell pair as illustrated in $\boldsymbol{A}$. For this pair, the mean ( \pm SEM) ulPSC latency was $3.6 \pm 0.08 \mathrm{~ms}$, mean ulPSC amplitude was $12.8 \pm 0.4 \mathrm{pA}$, and the probability of transmission was 0.7 . Note that the latency histogram is broader than is typical for a chemical synapse, probably reflecting the "Ioose-coupling" between calcium entry and vesicle release at CCK nerve terminals (Hefft and Jonas, 2005) (see Discussion).

\section{Identification of interneurons as basket cells}

Although a large percentage of CCK and PV cells are perisomatictargeting cells (or basket cells), cells expressing these markers can have other targets. For example, the SCA cells are a prominent CCK subgroup in CA1 and are synaptically coupled to one another (Ali, 2007). SCA cells have smaller somata than basket cells and are located predominantly in the outer portion of s. radiatum. They were significantly excluded by our search strategy, which targeted larger interneurons in the inner one-half of $s$. radiatum in which the CCK basket cells are mainly found. To ascertain the morphology of the synaptically coupled CCK $\rightarrow$ PV cells, the cells were first examined under confocal fluorescence microscopy. This established their immunohistochemical identity and confirmed that their axons invaded and ramified in s. pyramidale. We then reprocessed the sections for nickelenhanced $\mathrm{DAB}$ staining. Both axons were labeled by DAB, although of course it was no longer possible to distinguish them from each other, and cell morphology was then reconstructed (see Materials and Methods). Typical examples of the axonal arborizations of identified CCK and PV cells are shown in Figure 7. No extensive axonal projections appeared outside of s. pryamidale. Extensive axonal arborization within s. pyramidale identifies the cells as basket cells. These illustrations are representative of all 16 CCK and 5 PV interneurons that were reconstructed, and 
Table 3. Properties of interneurons determined during simultaneous whole-cell recordings from synaptically coupled pairs of cells

\begin{tabular}{|c|c|c|c|}
\hline & $\mathrm{CCK} \rightarrow \mathrm{PV}(n)$ & $\mathrm{CCK} \rightarrow \mathrm{CCK}(n)$ & $\mathrm{CCK} \rightarrow \operatorname{PYR}(n)$ \\
\hline Postsynaptic $R_{\text {input }}(\mathrm{M} \Omega)$ & $181.4 \pm 21.2(5)$ & $139.2 \pm 14.1(14)$ & $47.9 \pm 7.3(5)^{* *}$ \\
\hline $\mathrm{uIPSC} P_{r}^{a}$ & $\begin{array}{c}0.37-0.7 \\
(0.51 \pm 0.07)(4)\end{array}$ & $\begin{array}{c}0.23-0.84 \\
(0.54 \pm 0.08)(6)^{b}\end{array}$ & $\begin{array}{c}0.54-0.96 \\
(0.63 \pm 0.05)(6)\end{array}$ \\
\hline uIPSC amplitude (pA) & $\begin{array}{c}12.8-26.7 \\
(15.2 \pm 1.8)(4)\end{array}$ & $\begin{array}{c}8.9-23.2 \\
(15.4 \pm 2.0)(6)^{b}\end{array}$ & $\begin{array}{c}13.8-55.2 \\
(27.5 \pm 3.6)(6)^{*}\end{array}$ \\
\hline ulPSC latency (ms) & $\begin{array}{c}2.48-5.7 \\
(3.6 \pm 0.6)(4)\end{array}$ & $\begin{array}{c}2.7-5.7 \\
(3.7 \pm 0.5)(7)\end{array}$ & $\begin{array}{c}2.1-3.6 \\
(3.1 \pm 0.3)(6)\end{array}$ \\
\hline $\begin{array}{l}\text { Decay time constant of asynchronous } \\
\text { release, } \tau_{\mathrm{D} \text {-asynch }}(\mathrm{ms})^{c}\end{array}$ & $\begin{array}{c}922-1398 \\
(1104 \pm 148)(3)\end{array}$ & $\begin{array}{c}212-1095 \\
(684 \pm 177)(5)\end{array}$ & $\begin{array}{c}88-2013 \\
(725 \pm 297)(6)\end{array}$ \\
\hline Asynch/synch ${ }^{C}$ release ratio & $\begin{array}{c}1.5-16.7 \\
(10.8 \pm 4.7)(3)\end{array}$ & $\begin{array}{c}2.5-28.8 \\
(8.1 \pm 4.2)(5)\end{array}$ & $\begin{array}{c}3.5-12.2 \\
(5.9 \pm 1.7)(6)\end{array}$ \\
\hline
\end{tabular}

Determined as the percentage of trials (from totals of 50-195 trials per pair) on which a presynaptic action potential induced a ulPSC in the paired postsynaptic cell.

${ }^{b}$ Excludes one $C C K \rightarrow C C K$ pair with very large ulPSC amplitude (mean, $122.1 \pm 6.82 \mathrm{pA} ; n=139$ ).

'Asynchronous (asynch) release was induced by $0.5 \mathrm{~s}$ presynaptic action potential trains at $50 \mathrm{~Hz}$ and was quantified as the integral of the mean current trace from 15 trials per pair taken after the stimulation ended. Synchronous (synch) release was determined as the integral of the means of the first five stimuli in the same stimulus trains. Essentially no asynchronous release occurred during the first five stimuli.

*, **Significant difference from the other two groups at $p<0.05$ and $p<0.005$, respectively. One-way ANOVA, followed by pairwise multiple comparisons, was used. There were no significant differences in any other rows.

since the identical search strategies were used for physiological experiments, the positive identification of all reconstructed cells as basket cells strengthens the conclusion that, in general, we were successful in targeting these cells throughout.

\section{Asynchronous GABA release from CCK cells onto interneurons}

CCK cell transmission onto pyramidal also includes a major asynchronous component (i.e., large multiquantal responses persist after cessation of interneuronal action potential firing, particularly as the frequency of action potentials is raised from 10 to $50 \mathrm{~Hz}$ ) (Losonczy and Nusser, 2004; Földy et al., 2006). Moreover, in four of the CCK-PYR cell pairs, transmission was extremely weak and variable until the interneuronal action potential frequency was raised, at which point barrages of asynchronous IPSCs occurred. To determine whether asynchronous release was a general property of transmission from CCK interneurons, we induced $0.5 \mathrm{~s}$ presynaptic action potential trains of 10,20 , or $50 \mathrm{~Hz}$ in 14 coupled interneuron pairs. As illustrated in Figure 8, rapid repetitive activation of presynaptic CCK cells induced copious asynchronous GABA release onto PV or CCK interneurons as well as onto pyramidal cells. Individual asynchronous components persisted for up to 1-2 s after the end of the last action potential in a train. To quantify asynchronous release, we took the mean of 15 asynchronous release traces per cell and then integrated the area under the mean curve, obtaining a measure of total charge in $\mathrm{pC}$ crossing the membrane. The integrals were well fit by single-exponential functions, and the integrals and exponential decay time constants $\left(\tau_{\mathrm{D} \text {-asynch }}\right)$ were used to characterize asynchronous release (Fig. $8 B$ ). The $\tau_{\mathrm{D} \text {-asynch }}$ from CCK cells was variable, but did not vary as a function of the postsynaptic partner cell (Table 3 ). As the data did not differ, we combined all groups and obtained a mean $\tau_{\mathrm{D} \text {-asynch }}$ from CCK cells of $842 \pm 140 \mathrm{~ms}(n=14)$. Integrals of asynchronous release also did not differ as a function of postsynaptic cell type (Fig. $8 D$ ). To compare synchronous with asynchronous release, we compared the integral of the first five stimuli in the $50 \mathrm{~Hz}$ trains, when essentially no asynchronous release occurred (Fig. 8C), with the integral of the asynchronous release that occurred after the trains. The mean ratio of asynchronous/synchronous release for CCK transmission determined in this way was $\sim 8: 1(n=14)$. There was a good correlation between the degree of asynchronous and synchronous release measured by their integrals across all cells $\left(r^{2}=0.84 ; n=14\right)$ (Fig. $\left.8 E\right)$, suggesting that the variability between cells in asynchronous release probably reflects the variability in the sizes of the UIPSCs, rather than differences in the asynchronous release mechanisms. In any case, it appears that the nature of the postsynaptic target cell does not markedly influence the occurrence of asynchronous GABA release or other properties of GABA release at CCK synapses.

\section{Functional impact of CCK inhibitory inputs to synaptically coupled PV cells}

The results reported above establish that CCK cells make synaptic contacts onto PV cells, but do not directly reveal the functional impact of these contacts. To determine whether CCK inputs influence PV cell firing, we made several changes in our standard procedures: first, we used current-clamp rather than voltageclamp methods so that both cells could freely fire action potentials. Second, we switched to a K-gluconate-based whole-cell solution (see Materials and Methods), as the KCl-based solution would produce abnormal, $\mathrm{GABA}_{\mathrm{A}}$-mediated synaptic depolarizations that would affect the postsynaptic cell aphysiologically. Third, rather than inducing transmitter release by depolarizing the presynaptic CCK cell with DC injections, we activated it in a more nearly physiological manner with brief microiontophoretic pulses of acetylcholine (ACh). The microiontophoretic pipette containing $20 \mathrm{~mm}$ ACh was placed within $20-30 \mu \mathrm{m}$ of a putative CCK cell in s. radiatum; putative PV cells were patched in or near s. pyramidale, or in s. oriens. The two interneurons were separated by $\sim 200-500 \mu \mathrm{m}$. A constant backing current of $-15 \mathrm{nA}$ was applied to prevent ACh leakage, and brief ( $\leq 1 \mathrm{~s})$ positive currents of 300-500 nA were applied at intervals of 1.5-2 min.

In total, 86 pairs of interneurons were tested with ACh (i.e., 21 putative $\mathrm{PV}$ cells were patched with a biocytin-containing pipette and ACh was applied to 86 prospective CCK partners, from three to eight partners per PV cell). Characteristic fast spiking was induced in the PV cells by small steady depolarizing DC. In 10 cases, ACh application to a presynaptic interneuron was followed by a transient cessation of PV cell firing. When such coupling was found, the presynaptic cell was patched at the end of the physiological experiment by a fresh biocytin-containing whole-cell pipette and its responsiveness to iontophoretic ACh was directly tested. It was not possible simply to patch the CCK cell after ACh iontophoresis, as this would have required removing and replacing the ACh iontophoretic pipette with a whole-cell pipette, patching and recording from the CCK cell while maintaining the PV cell recording intact throughout. Instead, at the end of the 

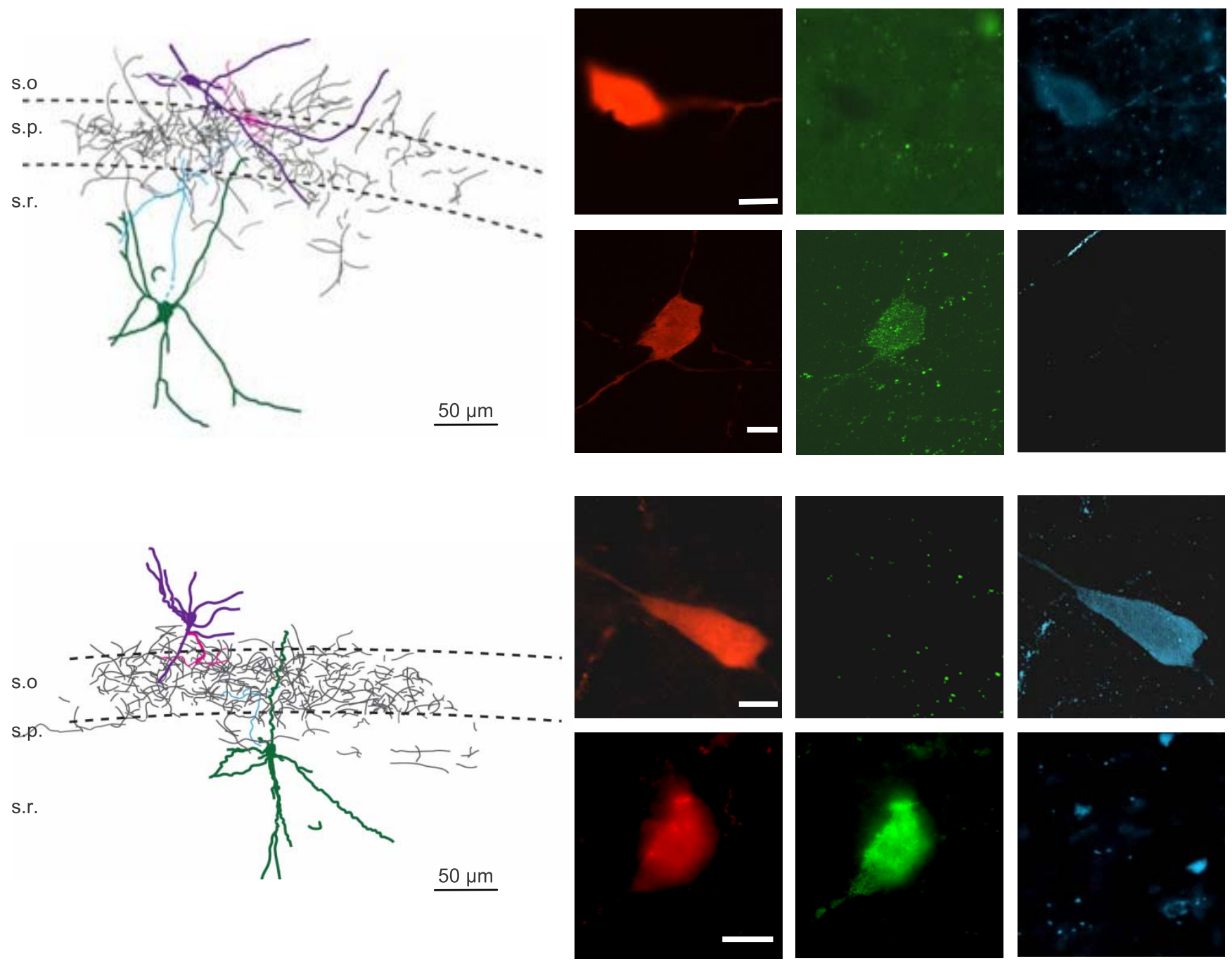

Figure 7. Examples of basket cell morphology of recorded CCK and PV cells in paired recordings. Tracings of two coupled CCK-PV pairs of cells shown in computer-aided (see Materials and Methods) reconstruction on left and as labeled immunocytochemically on right (left: biocytin, red; center: (CK, green; right: PV, blue). After electrophysiological recordings were performed with biocytin-filled pipettes, the slices were first fixed and labeled with fluorescent antibodies and photographed. The slices were then reprocessed for nickel-DAB staining, and computer-aided methods were used to trace the axons. DAB staining was required to detect the extensive axonal arborizations, and the identity of the individual axons was lost at that point. In the reconstructions, the cell somata and initial portions of the axons are shown in color because they were positively identified, but all axons are illustrated in dark gray. These reconstructions are typical of the five pairs processed in this way. The scale bar on the fluorescent images is $10 \mu \mathrm{m}$.

experiment, we removed the patch pipette from the PV cell, replaced it with a new dye-filled patch pipette, and used it to patch and label the CCK cell. The procedure kept the ACh pipette and CCK cell in the optical field and ensured that the correct cell was labeled. Subsequent immunocytochemical labeling confirmed the identity of all CCK and PV cells.

ACh application onto the CCK cells generally produced shortlatency (300 ms) depolarizations of $20-30 \mathrm{mV}$, accompanied by bursts of action potentials in the CCK cells. ACh had essentially no effect on the membrane potential of the PV cells when directly applied to them $(n=3)$ (data not shown). The CCK cell responses were variable, however, with some cells showing only brief depolarizations accompanied by vigorous action potential discharges (supplemental Fig. 2, available at www.jneurosci.org as supplemental material), and others showing slower and longer-lasting plateaus that gave rise to an initial burst of action potentials followed by lower-frequency firing. Like the CCK cell activation, the block of PV cell firing was variable in duration and ranged from 0.5 to $6 \mathrm{~s}$. The induced pause in PV cell firing was abolished by bath application of $20 \mu \mathrm{M}$ gabazine, showing that it had been caused by $\mathrm{GABA}_{\mathrm{A}}$ responses $(n=5)$. Figure $9 A$ illustrates a typical experiment, and Figure $9 B$ summarizes the group data from all pairs. Figure $9 C$ shows the labeled CCK and PV cell pair from which the data in Figure $9 A$ was obtained. In three pairs, subsequent application of $10 \mu \mathrm{M}$ atropine essentially abolished the ACh responses, confirming that they were mostly generated by activation muscarinic receptors (data not shown), although in some cases a small initial depolarization remained, consistent with the presence of nicotinic receptors on these cells (Freund, 2003).

The use of ACh iontophoresis facilitated the sampling of many potential cell pairs, and since ACh is rapidly taken up and degraded, it was unlikely to diffuse long distances and affect other cells. Moreover, for these experiments, we selected interneurons that were apart from other cells. We confirmed that ACh application was well localized, as the CCK cell action potential firing dropped off markedly with movements of the iontophoretic pipette of $20-50 \mu \mathrm{m}$ (supplemental Fig. 2, available at www. jneurosci.org as supplemental material), and no obvious network activity was induced. Nevertheless, ACh-sensitive processes of 


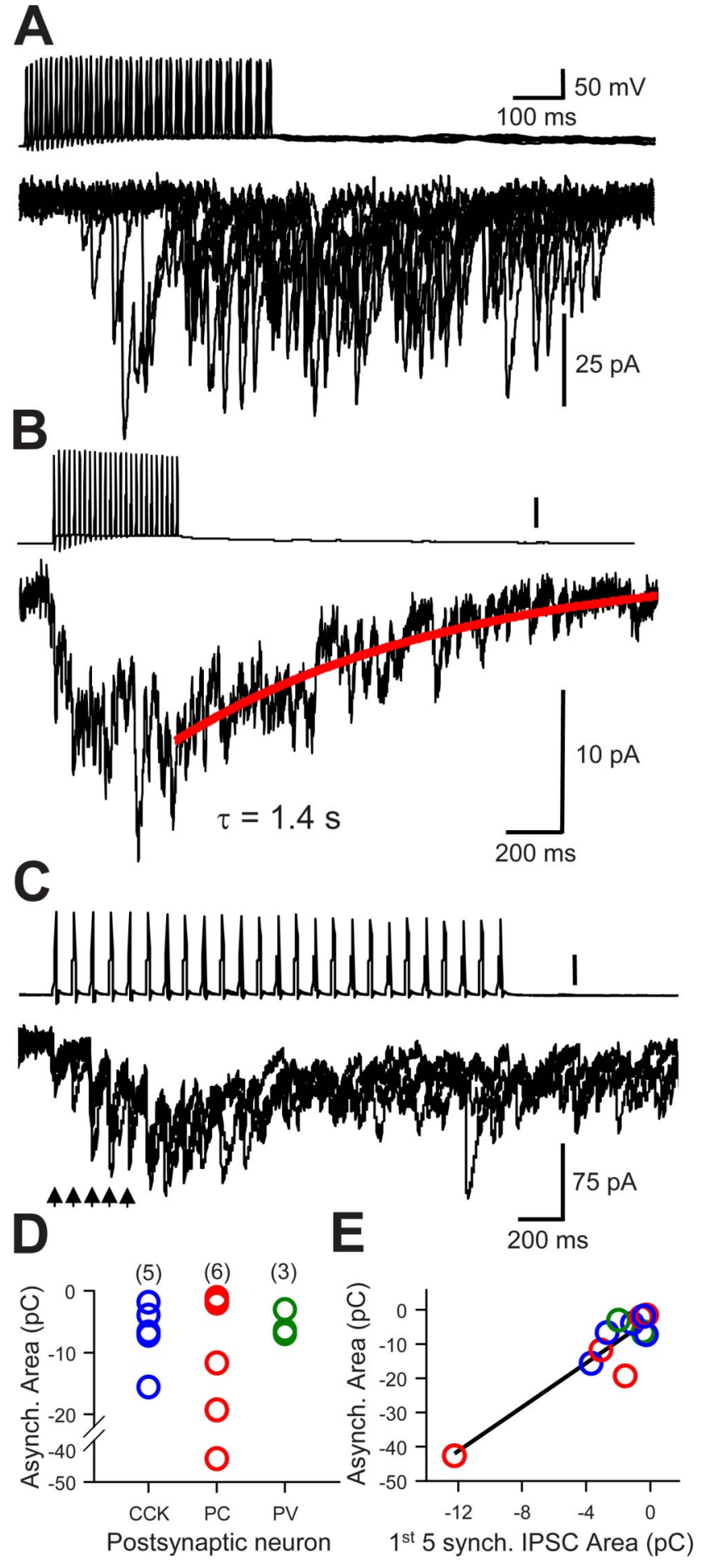

Figure 8. Asynchronous release from CCK cells interneurons. A, Asynchronous release from presynaptic CCK-interneuron to a PV cell. Synchronous uIPSCs were not evoked at the beginning of the $50 \mathrm{~Hz}$ train of presynaptic action potentials; however, copious asynchronous release was initiated after several presynaptic action potentials. Several trials overlapped to show the trialto-trial variability. $\boldsymbol{B}$, Integral of 15 trials from the same cells as in $\boldsymbol{A}$. The decay of the asynchronous release period is well fit by a single exponential function (red line) with a time constant of $1.4 \mathrm{~s}$. $\boldsymbol{C}$, Same format as in $\boldsymbol{B}$, in a CCK-CCK pair. Note the facilitation of the single uIPSCS throughout the initial part of the train (arrows), before asynchronous release becomes dominant. $\boldsymbol{D}$, Group data showing distributions of integrals (15 trials/cell pair) of asynchronous release from 14 paired-cell recordings having a CCK-cell as the presynaptic partner and postsynaptic cells as indicated; values of $n$ for each group are indicated above. $\boldsymbol{E}$, Relationship between integrals of asynchronous and synchronous release (calculated as the integrals of the first 5 uIPSCs in each train; 15 trials/cell pair) for the same cells as shown in $\boldsymbol{D}$. The straight line is the least-square regression fit to all of the points. other interneurons exist in s. radiatum, and these experiments could not rule out a contribution of such cells to the inhibition of PV cell firing. To test the physiological efficacy of CCK $\rightarrow$ PV connections more directly, we did two additional kinds of experiments. In one, after confirming that $\mathrm{ACh}$ iontophoresis onto a putative CCK cell inhibited firing of a coupled PV cell, we gradually moved the iontophoretic pipette farther away from the CCK cell soma while repeating the iontophoretic ACh release at intervals. As shown in supplemental Figure 3 (available at www.jneurosci.org as supplemental material), the intensity of PV cell inhibition dropped off as the ACh was delivered farther away. Thus, simply ejecting ACh into the nearby neuropil does not generally suffice to cause PV cell inhibition. In the second kind of experiment, we again searched for connected pairs of interneurons with whole-cell current-clamp recordings. A putative PV cell was depolarized slightly to induce action potential firing and a putative CCK cell was injected with a train of depolarizing current pulses $(50 \mathrm{~Hz}$ for $500 \mathrm{~ms}$ ) to induce a barrage of action potentials. As shown in Figure 10, action potential firing in the CCK cell was associated with an immediate cessation of PV cell action potential firing ( $n=2$ pairs). Figure $10 \mathrm{~A}$ also reveals the appearance of small IPSPs in the PV cell during the lull in action potentials. We were able to bath-apply gabazine to one of these pairs and confirm that the inhibition of PV action potential firing was caused by $\mathrm{GABA}_{\mathrm{A}}$ activation (Fig. $10 \mathrm{~B}$ ). In all cases, both PV and CCK cells were positively identified by immunohistochemical labeling at the end of the experiments. These data directly demonstrate that $\mathrm{CCK}$ innervation has physiologically significant, $\mathrm{GABA}_{\mathrm{A}^{-}}$ mediated effects on PV cells.

\section{Discussion}

Our data reveal that, in the hippocampal CA1 region, perisomatic-targeting CCK and PV interneurons are synaptically coupled. The evidence included immunocytochemical staining, EM morphology, and paired-interneuron electrophysiological recording. Given the similarity of CCK and PV networks throughout the cerebral cortex (Somogyi and Klausberger, 2005; Freund and Katona, 2007), the results may add a new dimension to the understanding of the organization of neuronal network behaviors in these regions.

Perisomatic-targeting interneurons regulate pyramidal cell firing patterns (Cobb et al., 1995; Miles et al., 1996; Pouille and Scanziani, 2001; Whittington and Traub, 2003). CCK and PV cells are key determinants of network oscillations in neuronal assemblies (Freund and Katona, 2007). Identified CCK and PV cells are strongly excited at different phases of hippocampal theta rhythm cycles in anesthetized animals (Klausberger et al., 2005). CCK cells are active on the ascending phase of the theta wave, whereas PV cells fire on the descending phase, $\sim 113^{\circ}$ apart. Evidently, the two cells play different roles in the cycle. An unanswered question is what determines the regular relationship between their firing patterns. Distinct excitatory inputs could initiate CCK and PV cell firing at different times (Klausberger et al., 2005). Alternatively, as suggested by the present data, direct synaptic interconnections between them could be involved. CCK and PV cell oscillations could be correlated, but necessarily out of phase because of the delays introduced by crossed inhibition.

An intriguing observation was that there are numerous axoaxonic contacts, defined with multiple immunofluorescence labeling and EM, between CCK and PV terminals. Reportedly, axoaxonic connections between glutamatergic afferents and GABAergic interneuron terminals in visual cortex induce IPSCs in the pyramidal cells (Ren et al., 2007). The 
generality of this perhaps controversial finding is not known; however, such hypothetical interactions would be compatible with pharmacological and physiological data (Földy et al., 2007; Karson et al., 2008), showing that PV and CCK cells can each affect the synaptic output of the other interneuron class. Local, axonal cross talk would fit with the localized regulation of synaptic transmission performed by the endocannabinoid system between pyramidal cells and the CCK synaptic terminals (Alger, 2002; Freund et al., 2003). Conceivably, synaptic communication among a small cluster of CCK and PV nerve terminals that also synapse on pyramidal cells could form a kind of microglomerulus (Fig. $5 E, F)$ that would permit fine adjustments in synaptic inputs to only a few pyramidal cells. In contrast, by affecting interneuronal somatic action potential generation, axosomatic and axodendritic synapses would affect all postsynaptic targets of the interneurons. The existence of $\mathrm{CCK} \rightarrow \mathrm{PV}$ contacts at different spatial scales opens up the possibility of diverse functional consequences (Whittington and Traub, 2003; Somogyi and Klausberger, 2005).

Morphological evidence for PV $\rightarrow$ CCK synapses was less extensive than for $\mathrm{CCK} \rightarrow \mathrm{PV}$ synapses (Table 2), and we did not detect PV $\rightarrow$ CCK coupling in somatic recordings. The sample size was limited, and synapses could be made so distal as to be undetectable from the whole-cell electrodes in somata; hence physiological PV $\rightarrow$ CCK interactions cannot be ruled out. Nevertheless, the results generally suggest that the PV cell influence on CCK cells is less marked than the reverse. In addition, CCK terminals have approximately five active zones per synaptic contact (Biró et al., 2006), suggesting another possible factor that could contribute to the relative predominance of $\mathrm{CCK} \rightarrow \mathrm{PV}$ transmission. In addition, although $\mathrm{CCK} \rightarrow \mathrm{PV}$ cell coupling was fairly reliable, it could be weak or nonexistent if the CCK cell fired at low frequency. Increasing the frequency of action potential firing caused the appearance of IPSCs in the PV cell. This agrees with previous reports (Losonczy and Nusser, 2004; Klausberger et al., 2005) that CCK cell GABA release is often unreliable at low stimulation frequencies and becomes more reliable as the frequencies increase. Yet there is a major unresolved issue in the $\mathrm{CCK} \rightarrow \mathrm{PV}$ pairs. Previously, unreliable $\mathrm{CCK} \rightarrow \mathrm{PYR}$ coupling was attributed to endocannabinoid release from the target pyramidal cell. However, PV cells do not release endocannabinoids. This issue will have to be evaluated directly at $\mathrm{CCK} \rightarrow \mathrm{PV}$ synapses.

CCK cells release GABA asynchronously onto principal cells in dentate gyrus (Hefft and Jonas, 2005), CA3 (Losonczy and Nusser, 2004), and CA1 (Földy et al., 2006). It was not known whether this occurs at CCK synapses onto other interneurons. Postsynaptic cells can influence the release properties of the synapses innervating them (Maccaferri et al., 1998; Reyes et al., 1998); hence it was necessary to address the issue directly. We now report that repetitive stimulation of CCK cells can release GABA asynchronously onto PV cells and other CCK cells. The
B
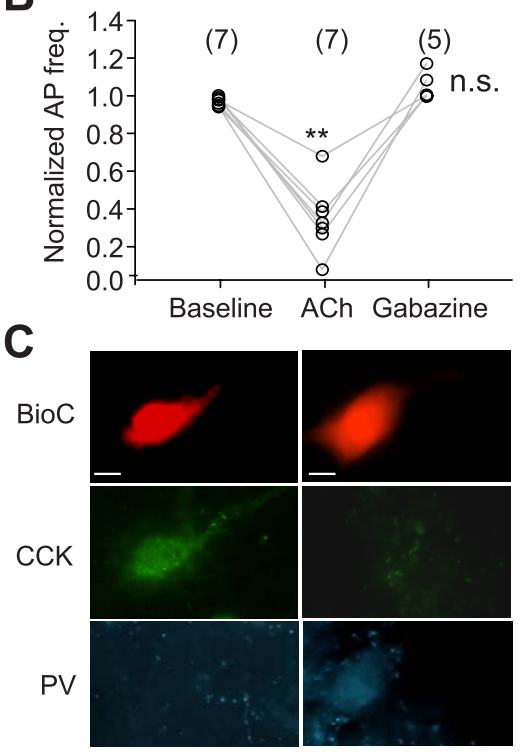

Figure 9. ACh stimulates CCK cells and inhibits action potential firing in synaptically coupled PV cells. $A$, The top trace illustrates $\mu \mathrm{m}$ gabazine, bath-applied, ACh application no longer inhibited PV cell firing. $\boldsymbol{B}$, Group data from seven experiments like

asynchronous release after a brief stimulus train decayed with a time constant of $\sim 842 \mathrm{~ms}$. This is the same order of magnitude as obtained by Hefft and Jonas (2005) for CCK-dentate granule cell asynchronous release ( $\sim 295 \mathrm{~ms})$, although these authors used a different method (deconvolution) to analyze asynchronous release. Our comparison of asynchronous to synchronous release yielded a mean ratio of 8:1, whereas Hefft and Jonas (2005) calculated a 3:1 ratio in the dentate gyrus. Our method should produce ratio values approximately twice as large as those of $\mathrm{Hefft}$ and Jonas, however, because we used synchronous release from only the first five stimuli in the train in the ratio, and they used responses to 10 stimuli. For comparison with their data, a better estimate of the asynchronous/synchronous ratio in our experiments would be $4: 1$. The important point is that both investigations agree that asynchronous release from CCK nerve terminals is likely to dominate over synchronous release when the cells are stimulated at moderately high frequencies. Our data also show that the CCK release process does not depend on the nature of the postsynaptic partner cell. Asynchronous release is a hallmark of a loose-coupling between calcium influx into nerve terminals and the calcium sensors for release (Xu-Friedman and Regehr, 2000; Hefft and Jonas, 2005). It has been suggested that the asynchronous release from CCK cells could provide a prolonged, fluctuating form of inhibition to the pyramidal cells (Hefft and Jonas, 2005). When vigorously activated, CCK cells will provide similar sustained inhibition to other interneurons as well. Although we could not record asynchronous release and PV cell inhibition simultaneously, the occasional long duration inhibition of PV cell firing could reflect prolonged asynchronous GABA release from the CCK cells.

Exogenous CCK excites PV interneurons (Neu et al., 2007; Karson et al., 2008); however, it has not thus far been shown that activation of CCK interneurons causes synaptic release of CCK. 

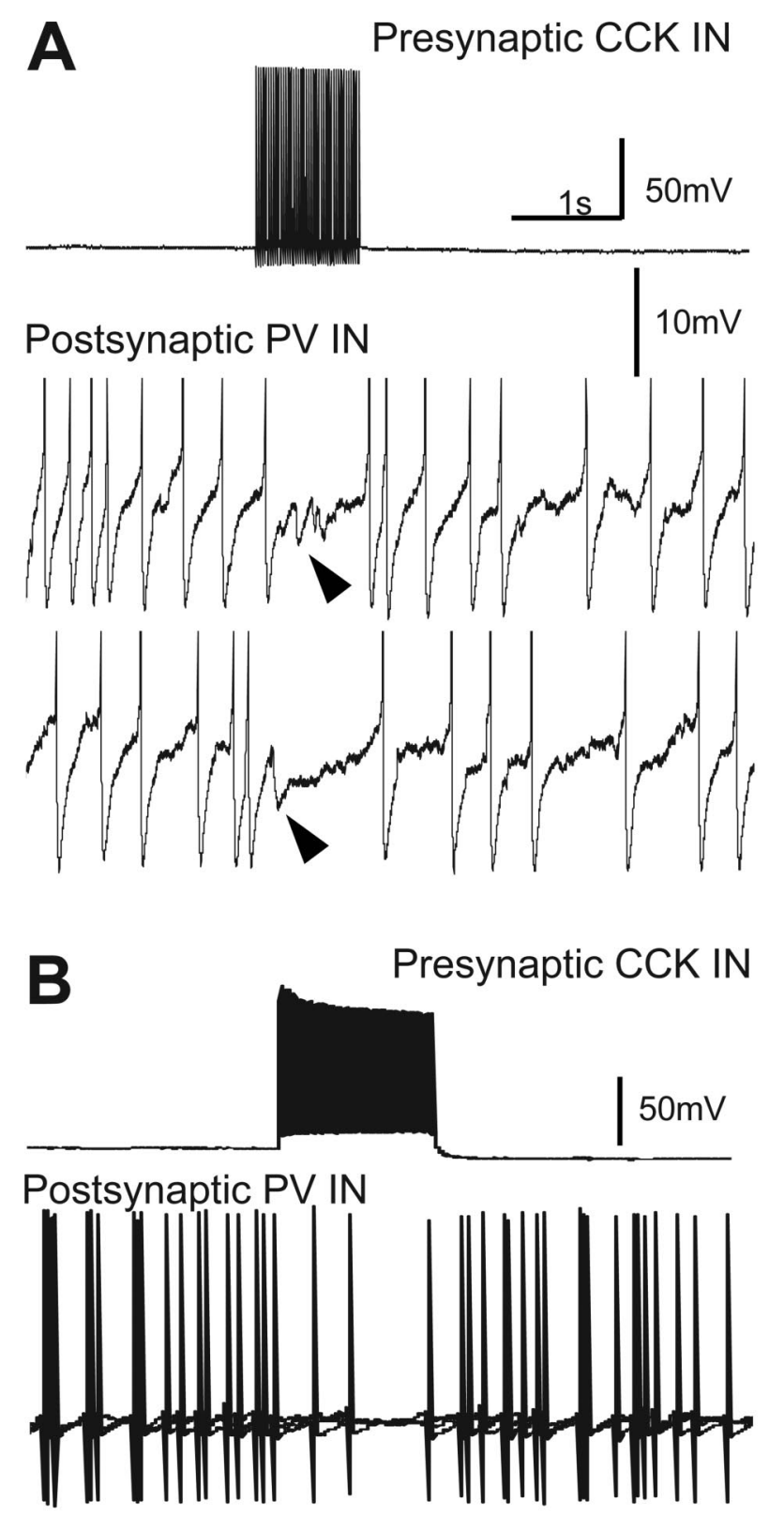

Gabazine

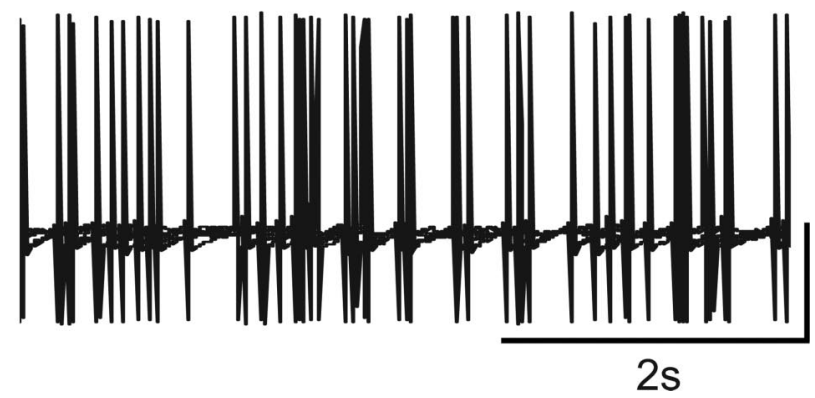

Figure 10. Action potential firing in a presynaptic CCK interneurons inhibits action firing in synaptically coupled PV cells. A, A 1 s depolarizing current injection into the CCK cell triggered a train of action potentials in that cell (top trace) and caused a temporary cessation of action potential firing in the coupled PV cell (middle and bottom traces). Small IPSCS (arrowheads) during lull in PV cell firing are shown. Note different voltage calibration bars in traces from CCK and PV cells. $\boldsymbol{B}$, Different CCK-PV pair than in $\boldsymbol{A}$. In control saline, $2 \mathrm{~s}$ train of action potentials in CCK cell suppressed PV cell action potential firing. Bath application of $20 \mu \mathrm{m}$ gabazine (bottom trace) prevented CCK cell inhibition of PV cell firing. Positive identification of all cells was subsequently established by immunohistochemical labeling (data not shown).
Although this could mean that CCK is not an excitatory transmitter in the hippocampus, another possibility is that the proper conditions for its release have not been found. Karson et al. (2008) showed that bath application of a mAChR agonist causes CCK-dependent effects on IPSPs. Discovering the conditions that cause physiological CCK release will be an important future task, as CCK could be the fulcrum for the balance of the actions between CCK and PV cells. For example, if a network of CCK cells and PV cells became dominated by PV cell activity, CCK cells would be inhibited, but this could have two opposing consequences: (1) decreasing GABAergic $\mathrm{CCK} \rightarrow \mathrm{PV}$ transmission would enable the PV cells to fire more, but (2) decreasing CCKmediated $\mathrm{CCK} \rightarrow \mathrm{PV}$ transmission would reduce the excitatory drive onto the PV cells. Conversely, strong activation of the CCK cells would both drive down PV cell activity via GABAergic inhibition, and yet prevent the PV cells from shutting down entirely by increasing CCK-mediated excitation. The combination of GABA and CCK would make possible delicate "thermostatic" control of the networks. Finally, it is interesting to consider the effects of endocannabinoids in this context. Released from pyramidal cells, they activate the $\mathrm{CB}_{1} \mathrm{R}$ on CCK terminals, thereby presumably reducing both GABA and CCK release from the terminals. In other words, although they do not themselves have $\mathrm{CB}_{1} \mathrm{Rs}$, PV cell output should be subtly affected by endocannabinoids via $\mathrm{CCK} \rightarrow \mathrm{PYR}$ cross talk. Exogenous cannabinoids do depress hippocampal gamma (Hájos et al., 2000) and theta (Robbe et al., 2006) rhythms, probably by disrupting spiketiming coordination, although endogenous cannabinoids were not implicated in the rhythm generation itself.

Consistent with previous EM studies (Harris et al., 1985; Mátyás et al., 2004), we also observed CCK-immunoreactive terminals forming synapses onto CCK-immunoreactive soma and dendrites at the ultrastructural level (data not shown), and we showed physiologically the existence of CCK $\rightarrow$ CCK synapses. Previous work had established that CCK cells of a different subclass, the SCA cells, innervate one another chemically (Ali, 2007); hence our data extends the range of CCK $\rightarrow \mathrm{CCK}$ interactions to perisomatic cells. Details of postsynaptic subcellular targeting heavily influences neuronal spatial and temporal coding functions (Somogyi and Klausberger, 2005), implying that chemical synaptic coordination may be a general feature of CCK participation in various behavioral actions.

In summary, our results suggest that the CCK interneurons influence the PV interneuron network. The particular effects will depend on the timing of the IPSPs, which could help entrain the PV cells, and the influence of CCK itself. Mutual inhibitory interactions could contribute to the sequential firing patterns of these cells in vivo (Klausberger et al., 2005), although the excitatory drives on the cells will provide the context in which such interactions can occur. Perhaps part of the fine-tuning performed by the CCK cells involves balancing these opposing forces onto the PV cells and contributes to the differentiation of pyramidal cells into different functional subgroups (Klausberger et al., 2005).

\section{References}

Acsády L, Katona I, Martínez-Guijarro FJ, Buzsáki G, Freund TF (2000) Unusual target selectivity of perisomatic inhibitory cells in the hilar region of the rat hippocampus. J Neurosci 20:6907-6919.

Alger BE (2002) Retrograde signaling in the regulation of synaptic transmission: focus on endocannabinoids. Prog Neurobiol 68:247-286.

Ali AB (2007) Presynaptic inhibition of $\mathrm{GABA}_{\mathrm{A}}$ receptor-mediated unitary IPSPs by cannabinoid receptors at synapses between CCK-positive interneurons in rat hippocampus. J Neurophysiol 98:861-869. 
Biró AA, Holderith NB, Nusser Z (2006) Release probability-dependent scaling of the postsynaptic responses at single hippocampal GABAergic synapses. J Neurosci 26:12487-12496.

Celio MR, Heizmann CW (1981) Calcium-binding protein parvalbumin as a neuronal marker. Nature 293:300-302.

Celio MR, Baier W, Schärer L, de Viragh PA, Gerday C (1988) Monoclonal antibodies directed against the calcium binding protein parvalbumin. Cell Calcium 9:81-86.

Cobb SR, Buhl EH, Halasy K, Paulsen O, Somogyi P (1995) Synchronization of neuronal activity in hippocampus by individual GABAergic interneurons. Nature 378:75-78.

Drake CT, Milner TA (2002) Mu opioid receptors are in discrete hippocampal interneuron subpopulations. Hippocampus 12:119-136.

Földy C, Neu A, Jones MV, Soltesz I (2006) Presynaptic, activity-dependent modulation of cannabinoid type 1 receptor-mediated inhibition of GABA release. J Neurosci 26:1465-1469.

Földy C, Lee SY, Szabadics J, Neu A, Soltesz I (2007) Cell type-specific gating of perisomatic inhibition by cholecystokinin. Nat Neurosci 10:1128-1130.

Freund TF (2003) Interneuron diversity series: rhythm and mood in perisomatic inhibition. Trends Neurosci 26:489-495.

Freund TF, Buzsáki G (1996) Interneurons of the hippocampus. Hippocampus 6:347-470.

Freund TF, Katona I (2007) Perisomatic inhibition. Neuron 56:33-42.

Freund TF, Katona I, Piomelli D (2003) Role of endogenous cannabinoids in synaptic signaling. Physiol Rev 83:1017-1066.

Fukudome Y, Ohno-Shosaku T, Matsui M, Omori Y, Fukaya M, Tsubokawa H, Taketo MM, Watanabe M, Manabe T, Kano M (2004) Two distinct classes of muscarinic action on hippocampal inhibitory synapses: M2mediated direct suppression and M1/M3-mediated indirect suppression through endocannabinoid signalling. Eur J Neurosci 19:2682-2692.

Galarreta M, Erdélyi F, Szabó G, Hestrin S (2004) Electrical coupling among irregular-spiking GABAergic interneurons expressing cannabinoid receptors. J Neurosci 24:9770-9778.

Gao Y, Bezchlibnyk YB, Sun X, Wang JF, McEwen BS, Young LT (2006) Effects of restraint stress on the expression of proteins involved in synaptic vesicle exocytosis in the hippocampus. Neuroscience 141:1139-1148.

Glickfeld LL, Scanziani M (2006) Distinct timing in the activity of cannabinoid-sensitive and cannabinoid-insensitive basket cells. Nat Neurosci 9:807-815.

Hájos N, Papp EC, Acsády L, Levey AI, Freund TF (1998) Distinct interneuron types express M2 muscarinic receptor immunoreactivity on their dendrites or axon terminals in the hippocampus. Neuroscience 82:355-376.

Hájos N, Katona I, Naiem SS, MacKie K, Ledent C, Mody I, Freund TF (2000) Cannabinoids inhibit hippocampal GABAergic transmission and network oscillations. Eur J Neurosci 12:3239-3249.

Harris KM, Marshall PE, Landis DMD (1985) Ultrastructural study of cholecystokinin-immunoreactive cells and processes in area CAl of the rat hippocampus. J Comp Neurol 233:147-158.

Hefft S, Jonas P (2005) Asynchronous GABA release generates long-lasting inhibition at a hippocampal interneuron-principal neuron synapse. Nat Neurosci 8:1319-1328.

Honer WG, Hu L, Davies P (1993) Human synaptic proteins with a heterogenous distribution in cerebellum and visual cortex. Brain Res 609:9-20.

Honer WG, Falkai P, Young C, Wang T, Xie J, Bonner J, Hu L, Boulianne GL, Luo Z, Trimble WS (1997) Cingulate cortex synaptic terminal proteins and neural cell adhesion molecule in schizophrenia. Neuroscience 78:99-110.

Karson MA, Whittington KC, Alger BE (2008) Cholecystokinin inhibits endocannabinoid-sensitive hippocampal IPSPs and stimulates others. Neuropharmacol 54:117-128.

Klausberger T, Marton LF, O’Neill J, Huck JH, Dalezios Y, Fuentealba P, Suen WY, Papp E, Kaneko T, Watanabe M, Csicsvari J, Somogyi P (2005) Complementary roles of cholecystokinin- and parvalbumin-expressing GABAergic neurons in hippocampal network oscillations. J Neurosci 25:9782-9793.

Kosaka T, Kosaka K, Tateishi K, Hamaoka Y, Yanaihara N, Wu JY, Hama K (1985) GABAergic neurons containing CCK-8-like and/or VIP-like im- munoreactivities in the rat hippocampus and dentate gyrus. J Comp Neurol 239:420-430.

Larsson LI, Rehfeld JF (1978) Distribution of gastrin and CCK cells in the rat gastrointestinal tract. Evidence for the occurrence of three distinct cell types storing $\mathrm{COOH}$-terminal gastrin immunoreactivity. Histochemistry 58:23-31.

Losonczy A, Nusser Z (2004) Persistently active cannabinoid receptors mute a sub-population of hippocampal interneurons. Proc Natl Acad Sci U S A 101:1361-1367.

Maccaferri G, Tóth K, McBain CJ (1998) Target-specific expression of presynaptic mossy fiber plasticity. Science 279:1368-1370.

Marsicano G, Lutz B (1999) Expression of the cannabinoid receptor CB1 in distinct neuronal subpopulations in the adult mouse forebrain. Eur J Neurosci 11:4213-4225.

Martin LA, Alger BE (1999) Muscarinic facilitation of the occurrence of depolarization-induced suppression of inhibition in rat hippocampus. Neuroscience 92:61-71.

Mátyás F, Freund TF, Gulyás AI (2004) Convergence of excitatory and inhibitory inputs onto CCK-containing basket cells in the CA1 area of the rat hippocampus. Eur J Neurosci 19:1243-1256.

Miles R, Tóth K, Gulyás AI, Hájos N, Freund TF (1996) Differences between somatic and dendritic inhibition in the hippocampus. Neuron 16:815-823.

Milner TA, McEwen BS, Hayashi S, Li CJ, Reagan LP, Alves SE (2001) Ultrastructural evidence that hippocampal alpha estrogen receptors are located at extranuclear sites. J Comp Neurol 429:355-371.

Mithani S, Atmadja S, Baimbridge KG, Fibiger HC (1987) Neurolepticinduced oral dyskinesias: effects of prograbide and lack of correlation with regional changes in glutamic acid decarboylase and choline acetyltransferase activities. Psychopharmacology (Berl) 93:94-100.

Neu A, Földy C, Soltesz I (2007) Postsynaptic origin of CB1-dependent tonic inhibition of GABA release at CCK-positive basket cell to pyramidal cell synapses in the CA1 region of the rat hippocampus. J Physiol 578:233-247.

Ohning GV, Wong HC, Lloyd KC, Walsh JH (1996) Gastrin mediates the gastric mucosal proliferative response to feeding. Am J Physiol 271:G470-G476.

Pawelzik H, Hughes DI, Thomson AM (2002) Physiological and morphological diversity of immunocytochemically defined parvalbumin- and cholecystokinin-positive interneurones in CA1 of the adult rat hippocampus. J Comp Neurol 443:346-367.

Peters A, Palay SL, Webster Hd (1991) The fine structure of the nervous system. New York: Oxford UP.

Pouille F, Scanziani M (2001) Enforcement of temporal fidelity in pyramidal cells by somatic feed-forward inhibition. Science 293:1159-1163.

Ren M, Yoshimura Y, Takada N, Horibe S, Komatsu Y (2007) Specialized inhibitory synaptic actions between nearby neocortical pyramidal neurons. Science 316:758-761.

Reyes A, Lujan R, Rozov A, Burnashev N, Somogyi P, Sakmann B (1998) Target-cell-specific facilitation and depression in neocortical circuits. Nat Neurosci 1:279-285.

Robbe D, Montgomery SM, Thome A, Rueda-Orozco PE, McNaughton BL, Buzsaki G (2006) Cannabinoids reveal importance of spike timing coordination in hippocampal function. Nat Neurosci 9:1526-1533.

Somogyi P, Klausberger T (2005) Defined types of cortical interneurone structure space and spike timing in the hippocampus. J Physiol 562:9-26.

Spray DC, Bennett MV (1985) Physiology and pharmacology of gap junctions. Annu Rev Physiol 47:281-303.

Tsou K, Mackie K, Sañudo-Peña MC, Walker JM (1999) Cannabinoid CB1 receptors are localized primarily on cholecystokinin-containing GABAergic interneurons in the rat hippocampal formation. Neuroscience 93:969-975.

Whittington MA, Traub RD (2003) Interneuron diversity series: inhibitory interneurons and network oscillations in vitro. Trends Neurosci 26:676-682.

Wilson RI, Nicoll RA (2001) Endogenous cannabinoids mediate retrograde signalling at hippocampal synapses. Nature 410:588-592.

Xu-Friedman MA, Regehr WG (2000) Probing fundamental aspects of synaptic transmission with strontium. J Neurosci 20:4414-4422. 